\title{
Does Parenting Context Modify Adolescents' Appraisals and Coping with a Situation of Parental Regulation? The Case of Autonomy-Supportive Parenting
}

\author{
Stijn Van Petegem ${ }^{1}$, Melanie J. Zimmer-Gembeck ${ }^{2}$, Bart Soenens ${ }^{3}$, Maarten Vansteenkiste ${ }^{3}$, Katrijn Brenning ${ }^{3}$, \\ Elien Mabbe ${ }^{3}$, Janne Vanhalst ${ }^{4}$, \& Grégoire Zimmermann ${ }^{1}$ \\ ${ }^{1}$ Family and Development Research Centre, Institute of Psychology, University of Lausanne, Lausanne, Switzerland \\ ${ }^{2}$ School of Applied Psychology and Griffith Health Institute, Behavioural Basis of Health Griffith University, \\ Australia \\ ${ }^{3}$ Department Of Developmental, Personality, and Social Psychology, Ghent University, Belgium \\ ${ }^{4}$ KU Leuven - University of Leuven, Belgium
}

This article may not exactly replicate the final version published in the journal. The final version is published in Journal of Child and Family Studies.

The exact reference is: Van Petegem, S., Zimmer-Gembeck, M., Soenens, B., Vansteenkiste, M., Brenning, K., Mabbe, E., Vanhalst, J., \& Zimmermann, G. (2017). Does general parenting context modify adolescents' appraisals and coping with parental regulation? The case of autonomy-supportive parenting. Journal of Child and Family Studies, 26, 2623-2639. 


\begin{abstract}
Theory and research suggest that adolescents differ in their appraisals and coping reactions in response to parental regulation. Less is known, however, about factors that determine these differences in adolescents' responses. In this study, we examined whether adolescents' appraisals and coping reactions depend upon parents' situation-specific autonomy-supportive or controlling communication style (i.e., the situation) in interaction with adolescents' past experiences with general autonomy-supportive parenting (i.e., the parenting context). Whereas in Study $1(N=176)$ adolescents' perceived general autonomy-supportive parenting context was assessed at one point in time, in Study $2(N=126)$ it was assessed multiple times across a 6-year period, allowing for an estimation of trajectories of perceived autonomy-supportive parenting context. In each study, adolescents read a vignette-based scenario depicting a situation of maternal regulation (i.e., a request to study more), which was communicated in either an autonomy-supportive or a controlling way. Following this scenario, they reported upon their appraisals and their anticipated coping reactions. Results of each study indicated that both the autonomy-supportive (relative to the controlling) situation and the perceived autonomy-supportive parenting context generally related to more positive appraisals (i.e., more autonomy need satisfaction, less autonomy need frustration), as well as to more constructive coping responses (i.e., less oppositional defiance and submission, more negotiation and accommodation). In addition, situation $\times$ context interactions were found, whereby adolescents growing up in a more autonomysupportive context seemed to derive greater benefits from the exposure to an autonomy-supportive situation and reacted more constructively to a controlling situation.
\end{abstract}

KEY WORDS: adolescence, parenting, coping, appraisal, autonomy, control, regulation 


\section{Introduction}

An important part of the socialization process includes parents' regulation of their offspring's behavior. During adolescence, regulation includes parents' active involvement in setting rules, communicating expectations, and formulating requests for more appropriate behavior when transgressions occur (Barber \& Xia, 2013). Low or inconsistent parental regulation can create a laissez-faire climate, putting adolescents at risk for externalizing and other problems (e.g., Collins, Maccoby, Steinberg, Hetherington, \& Bornstein, 2000; Galambos, Barker, \& Almeida, 2003). Recent research, however, suggests that adolescents differ strongly in their appraisals (i.e., interpretations) and reactions to specific situations of parental regulation (e.g., Kakihara \& Tilton-Weaver, 2009). This type of research is important because it contributes to a better understanding of children's and adolescents' active roles in shaping their own socialization (cf. Kuczynski, 2003; Soenens, Vansteenkiste, \& Van Petegem, 2015). Thus, it can

be expected that adolescents' appraisals and reactions to a situation of parental regulation may depend upon (a) parents' (autonomy-supportive vs. controlling) communication style (or, more briefly, the situation), (b) the perceived general autonomy-supportive parenting context (or, more briefly, the context), as well as (c) the interaction between situation and context.

According to Self-Determination Theory (SDT; Ryan \& Deci, 2000), one important determinant of adolescents' interpretations and reactions to a specific parenting situation is the quality of parents' communication style, which refers to the way in which rules and regulations are expressed and discussed (e.g., Vansteenkiste, Simons, Lens, Soenens, \& Matos, 2005). Thereby, SDT especially underscores the importance of distinguishing between an autonomy-supportive and a controlling communication style. An autonomy-supportive communication style involves encouraging adolescents to reflect upon and act in ways consistent with their personally endorsed goals and values (Grolnick, Deci, \& Ryan, 1997; Soenens et al., 2007). In the context of parental regulation and rule-setting, autonomy-supportive strategies involve being empathic towards the child, offering choice about how expectations can be met, being curious why children would refrain from sticking to rules, and providing a meaningful rationale for rules and requests. In contrast, a controlling communication style involves the use of coercion and intrusion, where parents pressure children to behave, feel, or think in ways prescribed by the parents (Grolnick, 2003; Soenens \& Vansteenkiste, 2010; Zimmer-Gembeck, Ducat, \& Collins, 2011). Controlling strategies for parental regulation include guilt induction, power assertion, conditional parental regard, and threatening with punishment (e.g., Assor, Roth, \& Deci, 2004; Rowe, Zimmer-Gembeck, Rudolph, Nesdale, \& 
Downey, 2015; Vansteenkiste et al., 2005). Although debate exists about whether an autonomy-supportive and a controlling style are orthogonal dimensions or rather opposite ends of one dimension, research suggests that a controlling style largely is incompatible with an autonomy-supportive style, when autonomy support is defined as the encouragement of children's self-endorsed functioning (Soenens \& Vansteenkiste, 2010; Soenens, Vansteenkiste, \& Sierens, 2009).

Parents' situation-specific communication style is likely to play a role in how adolescents appraise and cope with parents' attempts at regulating their behavior. According to SDT (Ryan \& Deci, 2000; Vansteenkiste \& Ryan, 2013), an autonomy-supportive style contributes to the satisfaction of adolescents' basic psychological need for autonomy; that is, when parents use an autonomy-supportive communication style, adolescents would be more likely to experience a sense of volition and psychological freedom in their actions. In the context of parental regulation, adolescents then would be more likely to feel that following their parents' rules is a personal choice and that the parental request is consistent with their personally endorsed values and interests. In contrast, a controlling style would frustrate the need for autonomy (Soenens \& Vansteenkiste, 2010). That is, adolescents then would feel pressured to behave, feel or think in a non-desired way. Previous research in the parenting context as well as in different domains (e.g., focusing on teacher communication styles) supports this notion (e.g., Chen, Soenens, Vansteenkiste, Van Petegem, \& Beyers, 2016; Reeve \& Jang, 2006; Van Petegem, Soenens, Vansteenkiste, \& Beyers, 2015; Vansteenkiste, Simons, Lens, Sheldon, \& Deci, 2004).

Moreover, parents' situation-specific communication style not only may affect adolescents' appraisals of the situation, but also how they would respond to (or cope with) the situation. As parental regulation involves a potential threat to adolescents' autonomy, four types of coping reactions are relevant (Skinner, Edge, Altman, \& Sherwood, 2003; Skinner \& Zimmer-Gembeck, 2007). First, one may react through oppositional defiance, which is a maladaptive response that involves a blunt rejection of the parental rule and a tendency to simply disregard the request (Deci \& Ryan, 1985; Vansteenkiste, Soenens, Van Petegem, \& Duriez, 2014). Submission is a second maladaptive way of responding, and involves ruminating about the situation and rigidly obeying the demand, thereby suppressing one's own personal preferences (Skinner \& Edge, 2002; Zimmer-Gembeck \& Skinner, 2011; see also Nolen-Hoeksema, 1998). Apart from these two maladaptive coping responses, two adaptive reactions are discerned as well. Accommodation refers to the flexible adjustment of one's own goals and priorities, for instance by cognitively restructuring the demand, by accepting the constraining situation or by focusing on more important goals 
(Brandtstädter \& Rothermund, 2002; Compas, Connor-Smith, Saltzman, Thomsen, \& Wadsworth, 2001; Morling \& Evered, 2006). Finally, negotiation involves the constructive articulation of disagreement by engaging in a dialogue with the parent, as to create a situation where a consensus can be reached between the external request and one's personally endorsed goals (Skinner \& Edge, 2002; Parkin \& Kuczynski, 2012).

As previous research suggests, parents' controlling communication style would relate to both more oppositional defiance (e.g., Chen et al., 2016; Van Petegem et al., 2016) and more submission (e.g., Assor \& Tal, 2012; Baudat, Zimmermann, Antonietti, \& Van Petegem, 2016) with regard to the parental request. By contrast, when parents communicate a request in an autonomy-supportive way, adolescents would be more likely to willfully adopt and accommodate to the parental request (Grolnick, 2003; Vansteenkiste et al., 2014). However, adolescents' appraisals and coping reactions not only would be function of the characteristics of the specific situation, but they also would depend upon the more general parenting context in which they have been raised (Skinner \& Edge, 2002; Zimmer-Gembeck \& Skinner, 2016). In this regard, Darling and Steinberg (1993) asserted that the general parenting style (i.e., the emotional climate in which the parent's behaviors are expressed) functions as a contextual factor that influences (i.e., moderates) the relationship between more specific parenting practices and specific outcomes. Similarly, Kuczynski (2003) argued that parent-child interactions need to be considered in the context of the parentchild relationship history. In other words, the accumulated history of interactions between parent and child has implications for how one interprets a new specific situation that occurs between a parent and his/her offspring, and how each understands a singular event and responds to it. This reasoning is consistent with a central tenet of symbolic interactionism (Blumer, 1969; Mead, 1934; see also Kuczynski, 2003), according to which specific situations are given meaning against the background of the larger social context in which the situation is embedded. Specifically with regard to situations of parental regulation, one may argue that when adolescents' parenting context has been generally autonomy-supportive, adolescents will be more sensitive to a new specific autonomy-supportive interaction and would derive a relatively greater degree of autonomy need satisfaction from this situation. By contrast, when the parenting context has been generally controlling for adolescents, they may be more sensitive for cues of control, thereby interpreting a controlling situation as more pressuring and experiencing more autonomy need frustration (Moller, Deci, \& Elliot, 2010). Technically, this reasoning implies moderation, where the positive effects of an autonomy-supportive situation are more pronounced among adolescents who grew up in an autonomy-supportive parenting context (i.e., a situation $\times$ context interaction). A number of recent social- 
psychological studies on relatedness frustration provided indirect evidence for the hypothesis of a situation $\times$ context interaction. Vanhalst and colleagues (2015), for instance, found that a history of relatedness frustration impacted responses to new interpersonal experiences. Specifically, they found that chronically lonely adolescents (who experienced repeated relatedness frustration in the past) were hypersensitive to new situations of social exclusion (i.e., they experienced more negative emotions) and hyposensitive to situations of social inclusion (i.e., they experienced less positive emotions). Moller et al. (2010) found that the more university students experienced relatedness satisfaction in their lives, the more they benefitted from new social encounters (i.e., they derived more need satisfaction from these encounters). Both studies demonstrate that individuals' history with need-based experiences affects their sensitivity to new needs-relevant situations, such that a history of need satisfaction increases individuals' sensitivity to the positive effects of a new need-satisfying event.

Alternatively, one might also argue that adolescents growing up in a more controlling environment would be more sensitive to the positive effects of an autonomy-supportive situation. An autonomy-supportive interaction would be more novel to them as it would stand in contrast with their previous experiences and they therefore would be disconfirmed in their expectancies about the situation, which would come as a "pleasant surprise" (see Gurland, Grolnick, \& Friendly, 2012; Oliver, 1993). Also, adolescents growing up in a more controlling environment would be in greater desire of autonomy need satisfaction and may, as such, benefit more from an autonomy-supportive situation. Indirectly supporting such reasoning, Radel, Pelletier, Sarrazin, and Milyavskaya (2011) found that the deprivation of autonomy increased individuals' sensitivity for cues related to autonomy satisfaction (i.e., it instigated a tendency to approach cues related to autonomy satisfaction and to avoid cues related to autonomy frustration). Extending this reasoning, one might expect that when adolescents grow up in a generally controlling familial context (and experienced long-term deprivation of their need for autonomy), they might be more sensitive for the positive effects of a new autonomy-supportive situation and therefore may appraise it in a more positive fashion.

Finally, the general parenting context may play a role in how adolescents cope with a specific situation of parental regulation. This is because parents play an important role in the socialization of children's coping, for instance through coaching and modeling mechanisms (e.g., Kliewer, Sandler, \& Wolchik, 1994; Power, 2004; Skinner \& Wellborn, 1994). Indeed, research has shown that adolescents growing up in generally supportive families use more constructive coping strategies (e.g., Seiffge-Krenke \& Pakalniskiene, 2011; Zimmer-Gembeck \& Locke, 2007). Hence, adolescents growing up in an autonomy-supportive family context likely respond more often 
with negotiation or accommodation, and less often with oppositional defiance or submission. Indeed, even in a situation where the parent would use a controlling communication style, adolescents growing up in a generally more autonomy-supportive context would have developed the necessary social skills and would have experienced sufficient safety in the past to negotiate under these circumstances (see Miklikowska, Duriez, \& Soenens, 2011); or, alternatively, these adolescents would accommodate, as they would be better able to see the underlying reasons or well-meant intentions of the parents' regulation, regardless of the way how it is communicated (Skinner \& Edge, 2002). Adolescents who grew up in a controlling parenting context, by contrast, may see any request for regulation as highly demanding and may lack the resources to deal adequately with such a situation; hence, these adolescents would rather engage in oppositional defiance and/or submission - especially when the request is communicated in a controlling way (Skinner \& Edge, 2002).

In two studies, we aimed at examining differences in adolescents' appraisals and coping with a situation of parental regulation, that is, a situation involving a parental demand to study more for school. We tested whether their appraisals and coping responses depend upon the situation (i.e., an autonomy-supportive vs. controlling situation), the general perceived autonomy-supportive parenting context, and the interaction between situation and context. First, we expected that adolescents' appraisals and coping responses would depend on the situation-specific communication style. Specifically, in response to the controlling (as opposed to the autonomy-supportive) situation, adolescents would report more perceived parental control and autonomy need frustration and less perceived parental autonomy support and autonomy need satisfaction. In addition, in the controlling situation, we expected adolescents to react more often through maladaptive coping (i.e., oppositional defiance, submission) and less often through adaptive coping (i.e., negotiation, accommodation). Second, we expected that adolescents' general perceptions of an autonomy-supportive parenting context would have a main effect on their appraisals and their coping responses, such that adolescents growing up in a generally more autonomy-supportive family would report more benign appraisals and more constructive coping. Finally, we also tested whether the perceived general parenting context moderated the relation between the situation-specific communication style and adolescents' appraisals and coping reactions.

\section{Study 1}

\section{Method}


Participants. The participants were 176 Belgian adolescents, ranging in age between 14 and 17 years $($ mean $=15.7$ years, $55 \%$ girls $)$. Most adolescents came from intact two-parent families $(83 \%)$ or divorced families $(15 \%)$, with the remaining adolescents reporting that one of the parents had deceased (2\%). Further, $67 \%$ of the participants followed an academic track, 25\% followed a technical track, $5 \%$ followed a vocational track, and $2 \%$ followed arts education. As for maternal highest educational degree, $1 \%$ of the mothers had completed elementary school, 41\% completed secondary school, 40\% attained a bachelor's degree, and 16\% had a master's degree. Information about educational level was missing for $2 \%$ of the mothers.

Procedure. Data were gathered by undergraduate students in the context of a course on developmental psychology in return for course credits. In a 1.5-hour session, the undergraduate students were explained about the goal of the study and about the recruitment procedures in order to ensure standardization of the procedure.

Specifically, they were asked to search for two families (no relatives or close friends) who were willing to take part in the study, and to visit the families at home. Students explained the purpose of the study, emphasized the voluntary nature of participation, and guaranteed confidential treatment of the data. Parents and the participating adolescents signed an informed consent. The adolescents filled out a number of general questionnaires, including a measure of perceived autonomy-supportive parenting context. While participants were filling out the questionnaires, the undergraduate students remained present to provide assistance if needed. A few days later, students visited the families again. During this meeting, the participants first read a vignette depicting a hypothetical situation. Previous research has shown the utility and the relevance of using a vignette-based approach for studying adolescents' interpretations of parent-adolescent interactions (e.g., Kakihara \& Tilton-Weaver, 2009; Pomerantz \& Eaton, 2000). Specifically, such an approach allows for the presentation of a situation in a detailed, context-specific and standardized way, and therefore is deemed as a valid methodology for studying participants' interpretations of a situation (e.g., Alexander \& Becker, 1978; Torres, 2009). As in previous research (e.g., Kakihara \& Tilton-Weaver, 2009), the vignette depicted a hypothetical interaction between a mother and an adolescent, and participants were instructed to imagine that they were in the situation. Specifically, participants first read a description of a situation where an adolescent comes home from school with poor grades. This situation was followed by a maternal reaction involving a request to study more, which was formulated either in an autonomy-supportive way (e.g., showing empathy, providing a rationale for the request) or in a controlling way (e.g., shaming, coercive language; Grolnick, 2003; Soenens \& Vansteenkiste, 2010). Extensive information about the development and the validity of the 
vignettes, as well as the materials as such, are provided by Van Petegem et al. (2015). Adolescents were randomly assigned to either the autonomy-supportive $(N=87)$ or the controlling $(N=89)$ condition. After reading the situation, participants filled out the questionnaires on their appraisals and anticipated coping reactions in the situation.

Measures. All items had five response options, ranging from 1 (“Completely not true") to 5 ("Completely true").

Perceived autonomy-supportive parenting context. Adolescents filled out a questionnaire tapping into their general perceptions of maternal autonomy-supportive (vs. psychologically controlling) parenting. Specifically, participants were administered two often-used questionnaires, that is, the 7-item Autonomy Support subscale of the Perceptions of Parents Scale (POPS; Grolnick, Ryan, \& Deci, 1991; e.g., "Whenever possible, my mother allows me to choose what to do") and the 8-item Psychological Control Scale of Barber (1996; e.g., "My mother is less friendly to me if I don't see things like she does"). There was a strong negative correlation between both scales $(r=-.62$, $p<.001)$. Therefore, as in previous research (e.g., Soenens et al., 2009), the latter items were reverse-coded as to create a reliable index of perceived autonomy-supportive vs. controlling parenting $(\alpha=.83)$.

Perceived parental autonomy support and parental control. After reading the situation, adolescents reported upon the degree to which they would perceive their mother as being autonomy-supportive or controlling in the described situation. Perceived parental autonomy support was assessed through four adjusted items of the Autonomy Support subscale of the POPS (Grolnick et al., 1991), adapted to the context of the hypothetical situation (e.g., "If my mother would react like this, I would feel like she allows me to decide things for myself", $\alpha=.85$ ). Perceived parental control was assessed through 4 items from the PCS (Barber, 1996), which were also adapted to the described situation (e.g., If my mother would react like this, I would feel like she is disappointed in me", $\alpha=$ $.86)$.

Autonomy need satisfaction and frustration. Participants reported upon the degree to which they would experience satisfaction or frustration of their basic psychological needs in the situation. This was done through an adapted version of the 24-item Basic Psychological Need Satisfaction and Frustration Scale (BPNSFS; Chen et al., 2015), which taps into satisfaction and frustration of the need for autonomy, relatedness, and competence (Chen et al., 2015). As our study focused specifically on the issue of adolescent autonomy, we only used the subscales assessing autonomy satisfaction and autonomy frustration. Four items tapped into adolescents' experienced 
autonomy need satisfaction (e.g., "If my mother would react like this, I would experience a sense of choice and freedom"), and four items tapped into adolescents' autonomy need frustration (e.g., "If my mother would react like this, I would feel forced to do things I wouldn't choose to do"). Both subscales were found to be reliable ( $\alpha=.88$ and .86 , for autonomy need satisfaction and autonomy need frustration, respectively).

Anticipated coping. Adolescents reported on how they would cope with the described situation. Oppositional defiance was assessed through a recently developed 4-item scale (Vansteenkiste et al., 2014; e.g., "I would rebel against the request of my mother"; "I would simply disregard the request"). The scale was found to be reliable $(\alpha=.85)$. Adolescents' inclination towards negotiation was assessed through an adapted version of the Negotiation subscale of the Child Coping Questionnaire (CCQ; Finnegan, Hodges, \& Perry, 1998; Ojanen \& Perry, 2007). The scale included 5 items (e.g., "I would explain my mother how I think about it"; "I would try to come to a good agreement with my mother") and was found to be reliable as well $(\alpha=.84)$.

Data Analysis. Before examining the main research questions, we tested the role of gender and age by performing a MANCOVA with gender as a fixed factor, age as a covariate, and the variables of interest as dependent variables. Our main analyses involved a series of regression analyses. Specifically, we examined the main effect of the situation (coded as $0=$ controlling situation and $1=$ autonomy-supportive situation), the main effect of perceived autonomy-supportive parenting context, and the interaction between both, in the prediction of each of the adolescents' appraisals and coping responses. We standardized all predictors and created interaction terms by multiplying the standardized terms. When interactions were significant, a simple slope test was used to examine the significance of the slopes under conditions of high levels (+1SD) and low levels (-1SD) of the moderator (Cohen, Cohen, West, \& Aiken, 2003; Dawson, 2014).

\section{Results}

Table 1 presents descriptive statistics and correlations between the variables of interest. The multivariate effects of gender and age were not significant $[F(6,166)=1.09, n s$, for gender; $F(6,166)=.83, n s$, for age $]$. Results of the hierarchical regression analyses are presented in Table 2. As for the prediction of adolescents' appraisals, adolescents in the autonomy-supportive situation, relative to those in the controlling situation, perceived the mothers' request as more autonomy-supportive and less controlling, and anticipated experiencing more autonomy need satisfaction and less autonomy need frustration. Moreover, there also was a significant main effect of perceived general autonomy-supportive parenting context on adolescents' appraisals in the described situation. Specifically, 
adolescents who reported growing up in a more autonomy-supportive parenting context reported more perceived situational autonomy support and less perceived parental control, and they anticipated experiencing more autonomy need satisfaction and less autonomy need frustration in the hypothetical situation. Finally, the interaction between situation and context was significant in the prediction of perceived parental autonomy support. Follow-up analyses indicated that the association between situation-specific communication style and perceived situational autonomy support was stronger among adolescents reporting higher levels of perceived general autonomy support $(b=.80$, $t(172)=10.28, p<.001)$, as compared to those reporting lower levels of perceived general autonomy support $(b=$ $.52, t(172)=6.71, p<.001$; see also Figure 1A). In other words, adolescents perceived most parental autonomy support when they were in the autonomy-supportive situation and grew up in a highly autonomy-supportive family context.

As for the coping response of oppositional defiance (see Table 2), it was found that adolescents in the autonomy-supportive, relative to the controlling, situation reported less oppositional defiance. Also as expected, adolescents who reported growing up in a context that was more autonomy-supportive reported less oppositional defiance in the situation. Context and situation did not interact in the prediction of oppositional defiance. The pattern was somewhat different for negotiation. Whereas adolescents in the autonomy-supportive (relative to the controlling) situation reported less negotiation, they reported more negotiation when perceiving their general parenting context as being more autonomy-supportive. More importantly, the interaction between situation and context was significant. As can be seen in Figure 1B, there only was a difference in negotiation between the two situations when adolescents perceived their parenting context as highly autonomy-supportive $(b=-.22, t(172)=-$ $2.80, p<.01)$. The relation between communication style condition and negotiation was non-significant among adolescents reporting low levels of perceived general autonomy support $(b=.00, t(172)=.01, n s)$. In other words, adolescents reported only reported higher levels of negotiation when they were in the controlling situation and grew up in a highly autonomy-supportive family.

\section{Discussion}

Study 1 provides insight into the question why adolescents differ in their appraisals and anticipated coping in response to a parental request to study more, thereby pointing to the role of situational characteristics (i.e., parents' situation-specific communication style) as well as the perceived general parenting context (i.e., whether they generally experience their mother as autonomy-supportive). In line with previous work on the effects of an 
autonomy-supportive as opposed to a controlling communication style (e.g., Vansteenkiste et al., 2005), adolescents in the autonomy-supportive situation clearly reported more positive appraisals, relative to those in the controlling situation: they perceived more parental autonomy support and less parental control and anticipated experiencing more autonomy need satisfaction and less autonomy need frustration. Moreover, adolescents in the controlling situation reported more oppositional defiance and negotiation, supporting the assumption that these coping reactions are especially salient when adolescents' feelings of autonomy are threatened (cf. Skinner \& Edge, 2002; Skinner et al., 2003). Such findings are congruent with recent research showing that autonomy deprivation may motivate people to engage in behaviors to restore their thwarted autonomy (e.g., Radel et al., 2011; Sheldon \& Gunz, 2009; van Prooijen, 2009). Interestingly, whether these restorative behaviors were adaptive (i.e., negotiation) or maladaptive (i.e., oppositional defiance) was largely function of the perceived parenting context in which the adolescent is raised. Indeed, as the situation $\times$ context interaction suggests, it is only when adolescents perceive their mother as generally autonomy-supportive that they are inclined to engage in negotiation when facing a controlling communication style in a specific situation. By contrast, adolescents growing up in an autonomy-suppressing context generally were inclined to react through oppositional defiance in reaction to both an autonomy-supportive and controlling communication of a specific request. These findings confirm that an autonomy-supportive family context might foster the development of adolescents' constructive coping skills (Kliewer et al., 1994; Power, 2004; Zimmer-Gembeck \& Skinner, 2016).

Finally, adolescents' general perceptions of the parenting context also played an important role in the prediction of adolescents' appraisals of the specific situation. That is, adolescents perceiving their parenting context as generally autonomy-supportive also tended to appraise the situation in a more benign fashion. Interestingly, we also obtained evidence for one situation $\times$ context interaction, indicating that adolescents from a perceived general autonomy-supportive parenting context especially appraised the autonomy-supportive situation as more autonomysupportive, indicating that they are more sensitive to novel need-supportive interactions (Moller et al., 2010). Stated differently, it seems that adolescents growing up in an autonomy-suppressing (i.e., controlling) family context have become relatively less sensitive to the potential benefits of new need-satisfying events (e.g., Radel et al., 2011; Sheldon, 2011). However, a longitudinal design is needed to truly examine whether adolescents' history of socialization colors new interactions.

\section{Study 2}


Although informative, the first study has two major limitations, which we aimed to overcome in Study 2.

First, Study 1 relied on a cross-sectional assessment to evaluate adolescents' perceived general autonomy-supportive parenting context. However, it is said that the enduring character of the parent-adolescent relationship is essential to understand more fully the dynamics of parent-child interactions (Kuczynski, 2003). Similarly, in past research examining the effects of the short-tern (or acute) vs. long-term (or enduring) frustration of one's basic psychological needs, the enduring experience to need frustration especially was found to be detrimental for one's functioning and instigated the process of desensitization (e.g., Radel et al., 2011; Vanhalst et al., 2015). Hence, Study 2 relied upon 4-wave longitudinal data - spanning six years - to chart adolescents' long-term history of perceived autonomysupportive parenting. Thereby, we used a person-centered approach (i.e., Latent Class Growth Analysis, LCGA; Nagin, 2005) in order to distinguish different trajectories of perceived general autonomy-supportive parenting context. This approach, where general perceptions of parenting context are assessed multiple times in vivo, helps to overcome problems (e.g., recall bias) associated with one-shot retrospective measures. In addition, doing so allowed us to differentiate adolescents' potentially periodic experiences of autonomy-supportive (vs. psychologically controlling) parenting from their accumulated history of experiences of autonomy-supportive parenting. Second, Study 1 assessed only two possible coping reactions, that is, oppositional defiance and negotiation. However, according to Skinner and colleagues (Skinner et al., 2003; Skinner \& Edge, 2002), people also may respond through submission or through accommodation when confronted with a threat to their autonomy. Therefore, all four coping reactions were assessed at Wave 4 of Study 2. Also, Study 2 made use of a within-person design rather than a between-person design, such that adolescents read both the controlling and the autonomy-supportive situation. The advantage of a within-person approach is the increased power of the design as well as a reduction of possible error caused by naturally occurring variance between groups. Moreover, by counterbalancing the order of presentation, possible order effects can be tested and taken into account (see e.g., Charness, Gneezy, \& Kuhn, 2012).

\section{Method}

Participants. The sample consisted of 127 adolescents (59.8\% girls) who had participated in a four-wave longitudinal study. Participants were retained for this study if they had participated at Time 4 (T4), because the hypothetical vignettes were only administered at T4. In total, 56 adolescents $(44.1 \%)$ participated at all four waves, 48 adolescents $(37.8 \%)$ at three of the four waves, 19 adolescents $(15 \%)$ at two of the four waves, and 4 adolescents (3.1\%) at one wave. Little's (1988) MCAR-test indicated that data were likely missing at random $\left(\chi^{2}(404)=403.99\right.$, 
$n s$ ), and therefore were treated through the Full Information Maximum Likelihood (FIML) procedure. At Time 1 (T1), the mean age of the participants was 12 years $(S D=1.7)$. The following three waves took place one year $(\mathrm{T} 2$; mean age $=13.1$ years $)$, four years $(\mathrm{T} 3 ;$ mean age $=16$ years $)$, and 5.5 years $(\mathrm{T} 4$; mean age $=17.4$ years $)$ after Wave 1. Most adolescents came from intact two-parent families (87\%). The remaining adolescents reported coming from divorced families $(9 \%)$, having one of the parents deceased (2\%), or had another family constellation (2\%). Almost all participants were students, either at high school (60\%), university or college (37\%), or another type of education $(2 \%)$.

Procedure. As in Study 1, participants were recruited in the context of a course on developmental psychology. At T1, students visited a family with a child between 8 and 14 years. Parents and the child signed an informed consent, and confidential treatment of the data was guaranteed. Then, the child filled out a number of questionnaires, including a measure of perceived autonomy-supportive parenting. For the following waves, the families were invited by phone to participate in the study. Upon their agreement, questionnaires were sent by regular mail and a stamped envelope was provided such that completed questionnaires could be sent back. At T4, adolescents not only filled out the general parenting questionnaire, but they also read the two hypothetical vignettes of Study 1, which were presented in a random order. After reading each of the vignettes, they filled out the situational questionnaires (assessing need satisfaction and frustration and anticipated coping) in response to each specific situation.

Measures. All items had five response options, ranging from 1 ("Completely not true") to 5 ("Completely true").

Perceived autonomy-supportive parenting context. At each point in time, we used the same questionnaires as in Study 1 to assess general perceived maternal autonomy-supportive and psychologically controlling parenting. As in Study 1, both scales correlated highly negatively ( $r$-values ranging between -.59 and -.75 , all $p \mathrm{~s}<.001$ ) and therefore were combined. Reliabilities ranged between .79 and .91 .

Situational autonomy need satisfaction and frustration. After reading each scenario, participants reported upon the degree to which they would experience need satisfaction and need frustration in that described situation. As in Study 1, we used the questionnaire developed by Chen et al. (2015). Because of length reasons, we shortened the questionnaire, such that six items assessed need satisfaction (with two items for each need) and six items assessed need frustration (also with two items for each need). To select the items, we first performed a Principal Component 
Analysis (PCA) on the data of Study 1, and then selected the highest loading items. As in Study 1, we only used the subscales assessing autonomy satisfaction and autonomy frustration. Reliabilities for autonomy need satisfaction were .86 and .94 , for the autonomy-supportive situation and for the controlling situation, respectively, and .73 and .83 for autonomy need frustration.

Anticipated coping. After reading each scenario, adolescents also reported on how they would cope with the described situation. We used the same scales as in Study 1 to measure oppositional defiance and negotiation. Further, a recent 7-item scale was used to assess whether adolescents would react through submission (Baudat et al., 2016; cf. Skinner \& Zimmer-Gembeck, 2007), that is, by giving up the personal preferences, rigidly obeying to the demand, and ruminating about the situation (e.g., "I would find it difficult to think about something else"; "I would comply submissively"). Finally, we assessed whether adolescents would respond through accommodation, which pertains to flexibly adjusting one's own goals and priorities, for instance, by accepting the current constraining situation or focusing on more important goals (Heckhausen, 1997; Skinner \& Edge, 2002). This scale consisted of six items, which were based upon items from the Secondary Control subscales of the Responses to Stress Questionnaire (Connor-Smith, Compas, Wadsworth, Thomsen, \& Saltzman, 2000) and the Acceptance subscale of the Cognitive Emotion Regulation Questionnaire (Garnefski \& Kraaij, 2006; e.g., "I would think by myself it is not such a big deal to do once what she asks"; "I would try to understand that my mother actually has well-meant intentions"). Reliabilities were, for the autonomy-supportive and the controlling situation, respectively, .86 and .88 for oppositional defiance, .86 and .85 for submission, .90 and .91 for negotiation, and .76 and .79 for accommodation.

Data Analysis. Before testing the main research questions, we examined whether order of presentation affected participants' responses, using a Repeated Measures (RM) MANOVA, with order as a between-subject factor, situation (autonomy support vs. control) and the order $\times$ situation interaction as within-subject factors, and the variables of interest as dependent variables. Then, we tested for gender and age differences through two separate RM MANCOVAs. In the first RM analysis, we added the four measurements of perceived autonomy-supportive parenting context as dependent variables, and gender as a between-subject factor, age as a between-subject covariate, and time point, and the time $\times$ gender interaction and time $\times$ age interaction as within-subject factors. In the second RM analysis, we added the appraisals (i.e., autonomy need satisfaction and frustration) and the coping reactions (i.e., oppositional defiance, submission, negotiation, accommodation) as dependent variables, and gender 
as a between-subject factor, age as a between-subject covariate, and situation (autonomy-supportive vs. controlling communication style), and the situation $\times$ gender interaction and situation $\times$ age interaction as within-subject factors.

In order to test our main hypotheses, we first performed LCGA using Mplus 7.00 (Muthén \& Muthén, 2012) as to identify different parenting context trajectories. Intercepts and slopes were modeled using the four measurements of perceived general autonomy-supportive parenting. Factor loadings of the intercepts were set to 1, and factor loadings for the slopes corresponded with the time interval (i.e., 0 at T1, 1 at T2, 4 at T3, and 5.5 at T4). We used several criteria to decide upon the number of classes. The Bayesian Information Criterion (BIC) for a solution with $k$ classes should be at least 10 points lower than for a solution with $k$ - 1 classes (Kass \& Raftery, 1995). Classification accuracy was assessed by entropy $(E)$, with values greater than .70 indicating accurate classification (Reinecke, 2006). Finally, the bootstrap Lo-Mendell-Rubin Test (Nylund, Asparouhov, \& Muthén, 2007) provides a $p$-value, which indicates whether there is a statistically significant improvement in fit, when including an additional class.

Then, we tested for the role of situation-specific communication style and of perceived general parenting context in the prediction of adolescents' appraisals and coping reactions. We performed two RM MANOVAs (for appraisal and for coping separately), with parenting context trajectory as a between-subject factor and with situation (autonomy-supportive vs. controlling communication style) and the situation $\times$ context interaction as within-subject factors.

\section{Results}

The RM MANCOVA that tested for possible ordering effects indicated no significant multivariate main effects of ordering $[F(6,120)=1.42, n s]$, nor for an interaction with situation $[F(6,120)=.41, n s]$. Then, we tested for gender and age differences in perceived general autonomy-supportive parenting. This RM MANCOVA also yielded no significant multivariate main effects of gender $[F(1,124)=.16, n s]$, age $[F(1,124)=.08, n s]$, or time point $[F(3,122)=2.31, n s]$, nor were the interactions significant $[F(3,122)=.63, n s$, for time $\times$ gender; $F(3,122)=$ $1.93, n s$, for time $\times$ age]. The second RM MANCOVA focused on gender and age differences in adolescents' appraisal and coping, thereby taking the within-subject variable situation into account. The analysis yielded no multivariate main effects of gender $[F(6,119)=1.90, n s]$ or age $[F(6,119)=1.78, n s]$. Further, the interaction between situation and age was not significant either $[F(6,119)=.35, n s]$, but the interaction with gender was 
$\left[F(6,119)=2.74, p<.05, \eta^{2}=.15\right]$. Subsequent univariate analyses indicated that the interaction was significant in the prediction of autonomy satisfaction $\left[F(1,124)=4.41, p<.05, \eta^{2}=.04\right]$, autonomy frustration $[F(1,124)=12.30$, $\left.p<.001, \eta^{2}=.11\right]$ and submission $\left[F(1,124)=12.31, p<.001, \eta^{2}=.11\right]$. Specifically, whereas in the autonomysupportive situation, boys had similar scores as girls for autonomy satisfaction $\left(M_{\text {boys }}=3.79\right.$ vs. $\left.M_{\text {girls }}=3.77\right)$ and slightly higher scores for autonomy frustration $\left(M_{\text {boys }}=2.49\right.$ vs. $\left.M_{\text {girls }}=2.20\right)$, the opposite pattern was obtained in the controlling situation, with girls scoring lower than boys for autonomy satisfaction $\left(M_{\text {boys }}=2.04 \mathrm{vs.} M_{\text {girls }}=1.56\right)$ and higher for autonomy frustration $\left(M_{\text {boys }}=3.46\right.$ vs. $\left.M_{\text {girls }}=3.95\right)$. Further, whereas boys and girls scored similarly for submission in the autonomy-supportive situation $\left(M_{\text {boys }}=1.90\right.$ vs. $\left.M_{\text {girls }}=1.86\right)$, girls scored clearly higher on submission in the controlling situation $\left(M_{\text {boys }}=2.35\right.$ vs. $\left.M_{\text {girls }}=2.85\right)$. Given these findings, gender was retained as a control variable in subsequent analyses.

Results of the LGCA estimations with 2-4 classes are presented in Table 3. Each of the selection criteria indicated that a three-class solution was most appropriate. Table 3 also presents intercepts and slopes for the classes. The first class $(N=65 ; 51 \%)$ was characterized by high initial levels of perceived general autonomy-supportive parenting context, which further increased across time, and therefore was labeled as a high-increasing (HI) trajectory. The second class $(N=53 ; 42 \%)$ was labeled as a moderate-stable (MS) trajectory, as it displayed moderate levels of perceived autonomy support, remaining stable across time. Finally, a small subgroup $(N=9 ; 7 \%)$ had relatively low initial levels for perceived general autonomy-supportive parenting context, which further decreased across time. This class was labeled as the low-decreasing $(L D)$ trajectory. The trajectories are graphically displayed in Figure 2.

As for the first RM MANOVA, predicting adolescents' appraisals, we found multivariate effects for situation $\left[F(2,123)=95.25, p<.001, \eta^{2}=.61\right]$, for context trajectory $\left[F(4,246)=2.55, p<.05, \eta^{2}=.04\right]$, and for the situation $\times$ context interaction $\left[F(4,246)=4.05, p<.01, \eta^{2}=.06\right] . F$-values and $\eta^{2}$-values for all subsequent univariate analyses are presented in Table 4 (top half). Replicating the findings of Study 1, a main effect of situation was found, with adolescents reporting significantly more autonomy need satisfaction $\left(M_{\mathrm{AS}}=3.61 \mathrm{vs}\right.$. $\left.M_{\mathrm{CON}}=1.75\right)$ and less autonomy need frustration $\left(M_{\mathrm{AS}}=2.45 \mathrm{vs} . M_{\mathrm{CON}}=3.91\right)$ in response to the autonomy-supportive, as compared to the controlling, situation. Similar to Study 1, the different trajectories of perceived general autonomy supportive context predicted experiences of autonomy need frustration, but not of autonomy satisfaction. Specifically, Tukey's HSD post hoc comparison showed that adolescents in the low-decreasing trajectory scored 
significantly higher on autonomy need frustration $\left(M_{\mathrm{LD}}=3.53\right.$ vs. $M_{\mathrm{MS}}=3.06$ and $\left.M_{\mathrm{HI}}=2.95\right)$, as compared to the other two trajectories. Finally, the interactions between condition and trajectory also were significant in the prediction of both autonomy satisfaction and frustration. As depicted in Figure 3, the difference between the two situations in autonomy need satisfaction and frustration was largest among adolescents in the high-increasing trajectory, suggesting that they derived the greatest benefits from the autonomy-supportive situation, in comparison to the two other parenting context trajectories.

The second RM MANOVA predicted adolescents' coping reactions in response to the parental request. Again, we found evidence for multivariate effects for situation $\left[F(4,121)=28.78, p<.001, \eta^{2}=.49\right]$, for context trajectory $\left[F(8,242)=5.65, p<.001, \eta^{2}=.16\right]$, and for the situation $\times$ context interaction $[F(8,242)=5.54, p<.001$, $\left.\eta^{2}=.16\right]$. As can be seen in Table 4 (bottom half), subsequent univariate analyses indicated significant effects of situation on each of the coping reactions. Specifically, in analogy with Study 1, in response to the autonomysupportive, as compared to the controlling, situation, adolescents reported less oppositional defiance $\left(M_{\mathrm{AS}}=1.84 \mathrm{vs}\right.$. $\left.M_{\mathrm{CON}}=2.53\right)$, and less negotiation $\left(M_{\mathrm{AS}}=3.50\right.$ vs. $\left.M_{\mathrm{CON}}=3.68\right)$, while, extending the findings of Study 1 , they also reported less submission $\left(M_{\mathrm{AS}}=2.08\right.$ vs. $\left.M_{\mathrm{CON}}=2.78\right)$ and more accommodation $\left(M_{\mathrm{AS}}=3.53\right.$ vs. $\left.M_{\mathrm{CON}}=3.12\right)$. A similar pattern as in Study 1 emerged as a function of general parenting context, with significant differences between trajectories being found for oppositional defiance, submission, and negotiation (but not for accommodation). Specifically, adolescents in the low-decreasing trajectory reported significantly more oppositional defiance as compared to those in the high-increasing group $\left(M_{\mathrm{LD}}=2.43\right.$ vs. $\left.M_{\mathrm{HI}}=1.91 ; M_{\mathrm{MS}}=2.22\right)$, as well as more submission as compared to the other two trajectories $\left(M_{\mathrm{LD}}=2.79\right.$ vs. $M_{\mathrm{MS}}=2.30$ and $\left.M_{\mathrm{HI}}=2.19\right)$. Adolescents in the high-increasing trajectory, by contrast, reported significantly more negotiation as compared to the other two trajectories $\left(M_{\mathrm{HI}}=4.06\right.$ vs. $M_{\mathrm{LD}}=3.28$ and $\left.M_{\mathrm{MS}}=3.42\right)$. Finally, the situation $\times$ context interactions were significant in the prediction of oppositional defiance, submission, and negotiation, and are depicted in Figure 4. Results for oppositional defiance and submission were similar. The difference between the two situations in oppositional defiance and submission was largest for adolescents in the high-increasing trajectory, relative to those in the two other trajectories, suggesting that adolescents growing up in an autonomy-supportive context benefit most from an autonomy-supportive communication style. As for negotiation, there seemed to be no difference between the two situations for adolescents in the high-increasing and moderate-stable trajectories, whereas adolescents in the lowdecreasing trajectory especially reported lower levels of negotiation in response to the autonomy-supportive, as 
compared to the controlling, situation.

\section{Discussion}

Study 2 offered further insight into the determinants of adolescents' interpretations and reactions to a maternal request to study more. In line with Study 1, the parents' situation-specific communication style played an important role, as adolescents reported more negative appraisals (i.e., less autonomy need satisfaction, more autonomy need frustration) and less constructive coping (i.e., more oppositional defiance, more submission, less accommodation, but more negotiation), when confronted with a controlling situation. In other words, these results corroborate the findings of Study 1 that showed that, in a situation where autonomy is threatened, behavioral responses are activated that aim at reclaiming freedom (i.e., adolescents reported more negotiation and oppositional defiance in response to the controlling situation; Radel et al., 2011). By contrast, when the threat to one's autonomy is relatively low (i.e., in the autonomy-supportive situation), adolescents especially seemed to accept and accommodate to the request; this is not surprising, as an autonomy-supportive communication style involves, among others, explaining the underlying reason of the request (Grolnick, 2003).

Further, making use of four-wave data spanning a six-year interval, we were able to distinguish three different trajectories of perceived autonomy-supportive parenting across the adolescent years, that is, a highincreasing, a moderate-stable and a low-decreasing group. Thereby, it is noteworthy that about half of the sample belongs to the high-increasing group: these adolescents perceived high initial levels of autonomy support, which only increased further across time. By contrast, we also identified a small group (7\%) following the opposite developmental trajectory across time: these adolescents reported relatively low initial levels of perceived autonomy support, and experienced even less parental autonomy support across time. These adolescents seem to experience chronic need frustration and are likely to be most at-risk for psychopathology (e.g., Sheldon, 2011; Vansteenkiste \& Ryan, 2013). In general, these findings suggest that there is considerable inter-individual variability in the way how adolescents' perceptions of their parents' rearing style develop throughout the adolescent years.

Results showed that adolescents' membership to these estimated parenting context trajectories played an important role in their interpretation and reaction to the hypothesized situation. In line with theorizing (e.g., Skinner \& Zimmer-Gembeck, 2007) and with Study 1, we found evidence for main effects of adolescents' parenting context trajectory. Adolescents in the high-increasing trajectory reported more constructive coping (i.e., more active negotiation), whereas adolescents in the low-decreasing trajectory reported a more negative interpretation of the 
situation (i.e., more autonomy need frustration) and a tendency to cope through maladaptive strategies (i.e., oppositional defiance and submission). More importantly, we also found consistent evidence that adolescents' perceived parenting context moderated the effects of situation on appraisal and coping. Specifically, adolescents in the high-increasing trajectory especially were most sensitive to the positive effects of an autonomy-supportive situation, both in terms of appraisals (i.e., greater autonomy need satisfaction, less autonomy frustration) and coping responses (i.e., less oppositional defiance, less submission). These findings are in line with the notion that responses to threats to the need for autonomy would depend on individuals' history of autonomy-relevant needs experiences, with a long-term, chronic exposure to autonomy need satisfaction being most beneficial (Radel et al., 2011). That is, adolescents in the high-increasing trajectory (i.e., those likely with a long-term history of need support) seem most sensitive for the beneficial effects of a new need-supportive situation as they derive the most autonomy need satisfaction and the least autonomy frustration from such a situation; in addition, these adolescents seem more likely to cope in constructive ways when facing a short-term deprivation of the need for autonomy (see also Vansteenkiste \& Ryan, 2013; Weinstein \& Ryan, 2011). By contrast, adolescents from the low-decreasing group (i.e., those likely with a history of chronic need frustration) seem less sensitive to the beneficial effects of a new need-supportive situation, and seem to lack the skills required to engage in more constructive coping. In fact, this group reported the lowest engagement in negotiation, while being highest in defiance and submission.

\section{General Discussion}

An important task for parents is to communicate rules and expectations for appropriate behavior (e.g., Barber \& Xia, 2013; Kochanska, Aksan \& Koenig, 1995; Maccoby, 2007). However, children are more than passive receivers of these messages - they also actively influence and shape their own socialization (Kakihara \& TiltonWeaver, 2009; Kuczynski, 2003; Soenens et al., 2015). In the present investigation, we examined how and why adolescents differ in their appraisals (i.e., interpretations) and in their coping reactions vis-à-vis a situation involving a parental request to study more for school. Using both cross-sectional and longitudinal data, we showed that their appraisals and coping responses depended upon characteristics of the situation as such (i.e., the maternal

communication style in that specific situation), the general parenting context in which the adolescent is growing up, as well as the interaction between both.

Consistent with theoretical principles (Ryan \& Deci, 2000) and with previous research (e.g., Pomerantz, Moorman \& Litwack, 2007; Van Petegem et al., 2015; Vansteenkiste et al., 2014), the current findings support the 
importance of implementing rules and communicating requests in an autonomy-supportive instead of a controlling way. Indeed, a controlling communication style clearly seemed less effective, as adolescents reported more negative appraisals (e.g., more autonomy need frustration) and more maladaptive reaction patterns (e.g., more oppositional defiance, less accommodation) in a controlling as opposed to an autonomy-supportive situation. Yet, adolescents' appraisals and coping responses were determined not only by the situation-specific communication style but also by their perception of growing up in a generally autonomy-supportive (vs. controlling) parenting context (Skinner \& Edge, 2002; Zimmer-Gembeck \& Skinner, 2016). Using both a cross-sectional variable-centered (Study 1) and a longitudinal person-oriented approach (Study 2) to chart the perceived general parenting context, we found evidence that the context affected adolescents' appraisals and coping reactions both directly (i.e., a main effect), but also modified their responses to specific situations (i.e., a situation $\times$ context interaction). Thus, adolescents' interpretations of the new parenting situation was partly colored by their previous socialization experiences, which is in line with a symbolic interactionist perspective (Blumer, 1969; Mead, 1934), as well as with Kuczynski's (2003) thesis that parent-child interactions should be understood in the context of the long-term relationship in which such interactions are embedded. In other words, it seems that adolescents' history of being exposed to an autonomysatisfying (vs. frustrating) environment sensitizes them for the benefits associated with new autonomy-satisfying situations (cf. Radel et al., 2011; Sheldon, 2011; Vanhalst et al., 2015). More specifically, we found that adolescents who perceived their mother to be more autonomy-supportive (Study 1) or who reported a history of accumulated maternal autonomy support (Study 2) seemed especially sensitive and receptive for new opportunities to experience need-support (i.e., the autonomy-supportive situation), as these adolescents perceived more parental autonomy support (Study 1) and derived a greater sense of autonomy need satisfaction and less autonomy need frustration (Study 2) from the autonomy-supportive situation specifically.

Moreover, adolescents with a perceived autonomy-supportive parenting history also were inclined to engage in more constructive coping (i.e., less oppositional defiance and submission, more negotiation), confirming the importance of the larger context in which children's coping skills develop (Kliewer et al., 1994; Power, 2004; Zimmer-Gembeck \& Skinner, 2016). The findings for negotiation were particularly intriguing. Whereas the findings of Study 1 suggest that adolescents from an autonomy-supportive family context were inclined to engage in negotiation in response to a controlling situation specifically, the findings of Study 2 indicated that those growing up in a family context of accumulated autonomy-support reported using more negotiation in response to both an 
autonomy-supportive and controlling situation. Overall, this pattern suggests that an autonomy-supportive home context is conducive to the development of adolescents' negotiation strategies, perhaps especially when adolescents feel pushed into an unwanted direction by their parents (i.e., in a controlling situation). Hence, an autonomysupportive parenting context may function as a resilience factor (cf. Vansteenkiste \& Ryan, 2013; Zimmer-Gembeck \& Skinner, 2016), possibly because these adolescents may have acquired greater social skills to engage in a constructive and open dialogue - even under potentially threatening conditions - through modeling (Kliewer et al., 1994; Power, 2004). Future research should investigate these possible mechanisms explaining the effect of autonomy-supportive parenting on appraisals and coping.

Finally, it is noteworthy that a perceived autonomy-supportive parenting context related to more negotiation, whereas associations with accommodation were non-significant. As the recent findings of Legault, Ray, Hudgins, Pelosi and Shannon (2017) suggest, the coping strategy of accommodation (which is more passive) may be socialized in a different way than the strategy of negotiation (which is more active). For instance, parental responsiveness might be a more important predictor for the development of accommodative strategies, as accommodation is relatively more relationally oriented and more focused on meeting the needs of the other (Finkel \& Campbell, 2001; Legault et al., 2017). However, future research is needed to examine this hypothesis. Similarly, future studies also could examine why some adolescents, growing up in controlling families, are more inclined to respond through oppositional defiance, whereas others rather would react through submission. Possibly, adolescents' personality profile may play a moderating role, with adolescents with a more high-inhibitory or overcontrolled profile being more likely to cope through submission, whereas those with a low-inhibitory or undercontrolled profile being more inclined to respond through oppositional defiance (Soenens et al., 2015; Zimmer-Gembeck \& Skinner, 2016).

\section{Limitations}

Although the present study had several strengths, including the vignette-methodology and the longitudinal design of Study 2, there are also a number of limitations that can be addressed in future work. Given the sole reliance upon self-reports and the use of hypothetical vignettes to assess adolescents' anticipated coping reaction to a parenting situation, future researchers may make use of different methodologies, such as standardized observations (see Altshuler, Genevro, Ruble, \& Bornstein, 1995). Further, given our unique focus on maternal parenting style, future research may examine whether our findings generalize to fathers' parenting style and may explore possible 
interactions between maternal and paternal parenting style. Moreover, future research could manipulate the content of the rules and requests formulated by parents, as the present study only focused on the specific situation of a parental request about an academic issue. Therefore, it would be important to investigate how children appraise and react to parental rule-setting in different domains of children's lives. Decision-making about moral issues, for instance, would remain to some extent more under the parents' jurisdiction even when adolescents grow older (Smetana, 1988, 2006). Personal issues, by contrast, are private aspects that pertain to adolescents' identity and are typically regulated by adolescents themselves, rather than by the parents (Nucci, 1996). Hence, whereas parental requests in the moral domain may be perceived less easily as a threat to the need for autonomy than requests in the academic domain, parental attempts at regulating the personal domain may especially be experienced as meddlesome and intrusive (see e.g., Kakihara \& Tilton-Weaver, 2009; Smetana, 2006; Van Petegem et al., 2016). Finally, the current study focused on how one specific microsystem (i.e., the general parenting context) affected adolescents' appraisals and coping responses. However, specific individual difference variables (e.g., personality) as well as macrosystem variables (e.g., cultural orientation) also may play an important role in determining how adolescents interpret and respond to specific parenting situations (Chen et al., 2016; Soenens et al., 2015; see also Bronfenbrenner \& Morris, 2006). Future research would do well broadening the scope in that respect as well. 


\section{Disclosure of Potential Conflicts of Interest}

The authors report no conflict of interests.

\section{Research involving Human Participants and/or Animals}

All procedures performed involving human participants in this study were in accordance with the ethical standards of the Ghent University Institutional Review Board and with the 1964 Helsinki declaration and its later amendments or comparable ethical standards.

\section{Informed Consent}

Informed consents were obtained from all participants included in the study.

\section{Author Contributions}

SVP coordinated the project, conceived of the study, analyzed and interpreted the data, and wrote the manuscript. MZG, BS and MV helped in the conception of the study, interpretation of the data, and writing the manuscript. KB helped in the data collection and in writing the manuscript. EM helped in writing the manuscript. JV helped in the analysis and interpretation of the data, and writing the manuscript. GZ helped in the interpretation of the data and in writing the manuscript. 


\section{References}

Alexander, C. S., \& Becker, H. J. (1978). The use of vignettes in survey research. Public Opinion Quarterly, 42, 93104. doi: $10.1086 / 268432$

Altshuler, J. L., Genevro, J. L., Ruble, D. N., \& Bornstein, M. H. (1995). Children's knowledge and use of coping strategies during hospitalization for elective surgery. Journal of Applied Developmental Psychology, 16, 53-76. doi: 10.1016/0193-3973(95)90016-0

Assor, A., Roth, G., \& Deci, E. L. (2004). The emotional cost of parents' conditional regard: A Self-Determination Theory approach. Journal of Personality, 72, 47-88. doi: 10.1111/j.0022-3506.2004.00256.x

Assor, A., \& Tal, K. (2012). When parents' affection depends on child's achievement: Parental conditional positive regard, self-aggrandizement, shame and coping in adolescents. Journal of Adolescence, 35, 249-260. doi: 10.1016/j.adolescence.2011.10.004

Barber, B. K. (1996). Parental psychological control: Revisiting a neglected construct. Child Development, 67, 3296-3319. doi: 10.1111/j.1467-8624.1996.tb01915.x

Barber, B. K. \& Xia, M. (2013). The centrality of control to parenting and its effects. In R. E. Larzelere, A. S. Morris, \& A. W. Harrist (Eds.), Authoritative parenting: Synthesizing nurturance and discipline for optimal child development. Washington, DC: APA.

Baudat, S., Zimmermann, G., Antonietti, J. P., \& Van Petegem, S. (2016). Maternal reaction to an adolescent alcohol use episode: Enforcing control will lead to change motivation? Drugs: Education, Prevention and Policy. Advance online publication. doi: 10.1080/09687637.2016.1192584

Blumer, H. (1969). Symbolic interactionism: Perspective and method. Englewood Cliffs, NJ: Erlbaum.

Brandtstädter, J., \& Rothermund, K. (2002). The life-course dynamics of goal pursuit and goal adjustment: A twoprocess framework. Developmental Review, 22,117-150.

Bronfenbrenner, U., \& Morris, P. A. (2006). The bioecological model of human development. In R. M. Lerner (Ed.), Handbook of Child Development: Vol. 1. Theoretical models of human development ( $6^{\text {th }}$ ed., pp.793-828). Hoboken, NJ: Wiley.

Charness, G., Gneezy, U., \& Kuhn, M. A. (2012). Experimental methods: Between-subject and within-subject design. Journal of Economic Behavior and Organization, 81, 1-8. doi: 10.1006/drev.2001.0539 
Chen, B., Soenens, B., Vansteenkiste, M., Van Petegem, S., \& Beyers, W. (2016). Where do the cultural differences in dynamics of controlling parenting lie? Adolescents as active agents in the perception of and coping with parental behavior. Psychologica Belgica, 56, 169-192. doi: 10.5334/pb.306.

Chen, B., Vansteenkiste, M., ..., \& Verstuyf, J. (2015). Basic psychological need satisfaction, need frustration, and need strength across four cultures. Motivation and Emotion, 39, 216-236. doi: 10.1007/s11031-014-9450-1

Cohen, J., Cohen, P., West, S. G., \& Aiken, L. S. (2003). Applied multiple regression/correlation analysis for the behavioral sciences ( $3^{\text {rd }}$ ed.). Mahwah, NJ: Erlbaum.

Collins, W. A., Maccoby, E. E., Steinberg, L., Hetherington, E. M., \& Bornstein, M. H. (2000). Contemporary research on parenting: The case for nature and nurture. American Psychologist, 55, 218-232. doi: 10.1037/0003-066x.55.2.218

Compas, B. E., Connor-Smith, J. K., Saltzman, H., Thomson, A. H., \& Wadsworth, M. E. (2001). Coping with stress during childhood and adolescence: Problems, progress, and potential in theory and research. Psychological Bulletin, 127, 87-127. Doi: 10.1037//0033-2909.127.1.87

Connor-Smith, J. K., Compas, B. E., Wadsworth, M. E., Thomsen, A. H., \& Saltzman, H. (2000). Responses to stress in adolescence: Measurement of coping and involuntary stress responses. Journal of Consulting and Clinical Psychology, 68, 976-992. Doi: 10.1080/10615800410001709412

Darling, N., \& Steinberg, L. (1993). Parenting style as context: An integrative model. Psychological Bulletin, 113, 487-496. doi: 10.1037//0033-2909.113.3.487

Dawson, J. F. (2014). Moderation in management research: What, why, when and how. Journal of Business Psychology, 29, 1-19. doi: 10.1007/s10869-013-9308-7

Deci, E. L., \& Ryan, R. M. (1985). Intrinsic motivation and self-determination in human behavior. New York, NY: Plenum.

Finkel, E. J., \& Campbell, W. K. (2001) Self-control and accommodation in close relationships: An interdependence analysis. Journal of Personality and Social Psychology, 81, 263-277. doi: 10.1037/0022-3514.81.2.263

Finnegan, R. A., Hodges, E. V. E., \& Perry, D. G. (1998). Victimization by peers: Associations with children's reports of mother-child interaction. Journal of Personality and Social Psychology, 75, 1076-1086.

Galambos, N. L., Barker, E. T., \& Almeida, D. M. (2003). Parents do matter: Trajectories of change in externalizing and internalizing problems in early adolescence. Child Development, 74, 578-594. 
Garnefski, N., \& Kraaij, V. (2006). The cognitive emotion regulation questionnaire: Development of a short 18-item version (CERQ-short). Personality and Individual Differences, 41, 1045-1053.

Grolnick, W. S. (2003). The psychology of parental control: How well-meant parenting backfires. Hillsdale, NJ: Lawrence Erlbaum Associates.

Grolnick, W. S., Deci, E. L., \& Ryan R. M. (1997). Internalization within the family: The self-determination theory perspective. In J. E. Grusec \& L. Kuczynski (Eds.), Parenting and children's internalization of values: A handbook of contemporary theory (pp. 135-161). New York, NY: Wiley.

Grolnick, W. S., Ryan, R. M., \& Deci, E. L. (1991). Inner resources for school achievement: Motivational mediators of children's perceptions of their parents. Journal of Educational Psychology, 83, 508-517.

Gurland, S. T., Grolnick, W. S., \& Friendly, R. W. (2012). The role of expectations in children's experience of novel events. Journal of Experimental Child Psychology, 113, 305-321. doi: 10.1037/e699552007-001

Heckhausen, J. (1997). Developmental regulation across adulthood: Primary and secondary control of age-related challenges. Developmental Psychology, 33, 176-187.

Kakihara, F., \& Tilton-Weaver, L. (2009). Adolescents' interpretations of parental control: Differentiated by domain and types of control. Child Development, 80, 1722-1738.

Kass, R. E., \& Raftery, A. E. (1995). Bayes factors. Journal of the American Statistical Association, 90, $773-795$.

Kliewer, W., Sandler, I., \& Wolchik, S. (1994). Family socialization of threat appraisal and coping: Coaching, modeling, and family context. In K. Hurrelman \& F. Nestmann (Eds.), Social networks and social support in childhood and adolescence (pp. 271-291). New York, NY: de Gruyter.

Kochanska, G., Aksan, N., \& Koenig, A. L. (1995). A longitudinal study of the roots of preschoolers' conscience: Committed compliance and emerging internalization. Child Development, 66, 1752-1769. doi: 10.1111/j.1467-8624.1995.tb00963.x

Kuczynski, L. (2003). Beyond bidirectionality: Bilateral conceptual frameworks for understanding dynamics in parent-child relations (pp. 1-24). In L. Kuczynski (Ed.), Handbook of dynamics in parent-child relations. Thousand Oaks, CA: Sage.

Legault, L., Ray, K., Hudgins, A., Pelosi, M., \& Shannon, W. (2017). Assisted versus asserted autonomy satisfaction: Their unique associations with wellbeing, integration of experience, and conflict negotiation. Motivation \& Emotion, 41, 1-21.doi: 10.1007/s11031-016-9593-3 
Little, R. (1988). A test of missing completely at random for multivariate data with missing values. Journal of the American Statistical Association, 83, 1198-1202. doi: 10.1080/01621459.1988.10478722

Maccoby, E. E. (2007). Historical overview of socialization research and theory. In J. E. Grusec, P. D. Hastings (Eds.), Handbook of socialization: Theory and research (pp. 13-41). New York, NY: Guilford Press.

Mead, G. H. (1934). Mind, self and society from the point of view of a social behaviorist. Chicago, IL: University Press of Chicago.

Miklikowska, M., Duriez, B., \& Soenens, B. (2011). Family roots of empathy-related characteristics: The role of perceived maternal and paternal need support in adolescence. Developmental Psychology, 47, 1342-1352.

Moller, A. C., Deci, E. L. \& Elliot, A. J. (2010). Person-level relatedness and the incremental value of relating. Personality and Social Psychology Bulletin, 36, 754-767.

Morling, B., \& Evered, S. (2006). Secondary control reviewed and defined. Psychological Bulletin, 132, $269-296$.

Miklikowska, M., Duriez, B., \& Soenens, B. (2011). Family roots of empathy-related characteristics: The role of perceived maternal and paternal need support in adolescence. Developmental Psychology, 47, 1342-1352.

Muthén, L. K., \& Muthén, B. O. (20012). Mplus user's guide (7th ed.). Los Angeles, CA: Muthén \& Muthén.

Nagin, D. S. (2005). Group-based modeling of development. Cambridge, MA: Harvard University Press.

Nolen-Hoeksma, S. (1998). Ruminative coping with depression. In J. Heckhausen \& G. S. Dweck (Eds.), Motivation and self-regulation across the life span (pp. 237-256). Cambridge, UK: Cambridge University Press.

Nucci, L. (1996). Morality and personal freedom. In E. S. Reed, E. Turiel, \& T. Brown (Eds.), Knowledge and values (pp. 41-60). Mahwah, NJ: Lawrence Erlbaum.

Nylund, K. L., Asparoutiov, T., \& Muthen, B. O. (2007). Deciding on the number of classes in latent class analysis and growth mixture modeling: A Monte Carlo study. Structural Equation Modeling, 14, 535-569.

Ojanen, T., \& Perry, D. G. (2007). Relational schemas and the developing self: Perceptions of mother and of self as joint predictors of early adolescents' self-esteem. Developmental Psychology, 43, 1474-1483.

Oliver, R. L. (1993). Cognitive, affective, and attribute bases of the satisfaction response. Journal of Consumer Research, 20, 418-430. doi: 10.1086/209358

Parkin, C. M., \& Kuczynski, L. (2012). Adolescent perspectives on rules and resistance within the parent-child relationship. Journal of Adolescent Research, 27, 632-658. doi: 10.1177/0743558411435852

Pomerantz, E. M., \& Eaton, M. M. (2000). Developmental differences in children's conceptions of parental control: 
“They love me, but they make me feel incompetent”. Merill-Palmer Quarterly, 46, 140-167. doi:

10.1111/j.2040-0209.2010.00352_2.X

Pomerantz, E. M., Moorman, E. A., \& Litwack, S. D. (2007). The how, whom, and why of parents' involvement in children's academic lives: More is not always better. Review of Education Research, 77, 373-410. doi: $10.3102 / 003465430305567$

Power, T. G. (2004). Stress and coping in childhood: The parents' role. Parenting: Science and Practice, 4, 271317. doi: 10.1207/s15327922par0404_1

Radel, R., Pelletier, L. G., Sarrazin, P, \& Milyavskaya, M. (2011). Restoration process of the need for autonomy: The early alarm stage. Journal of Personality and Social Psychology, 101, 919-934. doi: 10.1037/a0025196

Reeve, J., \& Jang, H. (2006). What teachers say and do to support students' autonomy during a learning activity. Journal of Educational Psychology, 98, 209-218. doi: 10.1037/0022-0663.98.1.209

Reinecke, J. (2006). Longitudinal analysis of adolescent's deviant and delinquent behavior. Methodology, 2, 100112. doi: $10.1027 / 1614-2241.2 .3 .100$

Rowe, S., Zimmer-Gembeck, M. J., Rudolph, J., Nesdale, D., \& Gowney, G. A. (2015). A longitudinal study of rejecting and autonomy-restrictive parenting, rejection sensitivity, and socioemotional symptoms in early adolescents. Journal of Abnormal Child Psychology, 43, 1107-1118. doi: 10.1007/s10802-014-9966-6

Ryan, R. M., \& Deci, E. L. (2000). Self-determination theory and the facilitation of intrinsic motivation, social development, and well-being. American Psychologist, 55, 68-78. doi: 10.1037//0003-066x.55.1.68

Seiffge-Krenke, I., \& Pakalniskiene, V. (2011). Who shapes whom in the family: Reciprocal links between autonomy support in the family and parents' and adolescents' coping behaviors. Journal of Youth and Adolescence, 40, 983-995. doi: 10.1007/s10964-010-9603-9

Sheldon, K. M. (2011). Integrating behavioral-motive and experiential-requirement perspectives on psychological needs: A two process model. Psychological Review, 118, 552-569. doi: 10.1037/a0024758

Sheldon, K. M., \& Gunz, A. (2009). Psychological needs as basic motives, not just experiential requirements. Journal of Personality, 77, 1467-1492. doi: 10.1111/j.1467-6494.2009.00589.x

Skinner, E. A., \& Edge, K. (2002). Self-determination, coping and development. In E. L. Deci \& R. M. Ryan (Eds.), Self-determination theory: Extensions and applications (pp. 297-337). Rochester, NY: University of Rochester Press. 
Skinner, E. A., Edge, K., Altman, J., \& Sherwood, H. (2003). Searching for the structure of coping: A review and critique of category systems for classifying ways of coping. Psychological Bulletin, 129, 216-269. doi: 10.1037/0033-2909.129.2.216

Skinner, E. A., \& Wellborn, J. G. (1994). Coping during childhood and adolescence: A motivational perspective. In R. Lerner, D. Featherman, \& M. Perlmutter (Eds.), Lifespan development and behavior (pp. 91-133). Hillsdale, NJ: Erlbaum.

Skinner, E. A., \& Zimmer-Gembeck, M. J. (2007). The development of coping. Annual Review of Psychology, 58, 119-144. doi: 10.1146/annurev.psych.58.110405.085705

Smetana, J. G. (1988). Adolescents' and parents' conceptions of parental authority. Child Development, 39, 321335. doi: $10.2307 / 1130313$

Smetana, J. G. (2006). Social-cognitive domain theory: Consistencies and variations in children's moral and social judgments. In M. Killen \& J. G. Smetana (Eds.), Handbook of moral development (pp. 119-153). Mahwah, NJ: Lawrence Erlbaum.

Soenens, B., \& Vansteenkiste, M. (2010). A theoretical upgrade of the concept of parental psychological control: Proposing new insights on the basis of self-determination theory. Developmental Review, 30, 74-99. doi: 10.1016/j.dr.2009.11.001

Soenens, B., Vansteenkiste, M., Lens, W., Luyckx, K., Goossens, L., Beyers, W., \& Ryan, R. M. (2007). Conceptualizing parental autonomy support: Adolescent perceptions of promotion of independence versus promotion of volitional functioning. Developmental Psychology, 43, 633-646. doi: 10.1037/00121649.43.3.633

Soenens, B., Vansteenkiste, M., \& Sierens, E. (2009). How are psychological control and autonomy support related? A cluster-analytic approach. Journal of Marriage and the Family, 71, 187-202. doi: 10.1111/j.17413737.2008.00589.x

Soenens, B., Vansteenkiste, M., \& Van Petegem, S. (2015). Let us not throw out the baby with the bathwater: Applying the principle of 'universalism without uniformity' to autonomy-supportive and controlling parenting. Child Development Perspectives, 9, 44-49. Doi: 10.1111/cdep.12103

Torres, S. (2009). Vignette methodology and culture-relevance: Lessons learned through a project on successful aging with Iranian immigrants to Sweden. Journal of Cross-Cultural Gerontology, 24, 93-114. doi: 
10.1007/s10823-009-9095-9

Vanhalst, J., Soenens, B., Luyckx, K., Van Petegem, S., Weeks, M. S., \& Ascher, S. R. (2015). Why do the lonely stay lonely? Chronically lonely adolescents' attributions and emotions in situations of social inclusion and exclusion. Journal of Personality and Social Psychology, 109, 932-948. doi: 10.1037/pspp0000051

Van Petegem, S., Soenens, B., Vansteenkiste, M., \& Beyers, W. (2015). Rebels with a cause: Adolescent defiance from the perspective of Reactance Theory and Self-Determination Theory. Child Development, 86, 903918. doi: $10.1111 /$ cdev.12355

Van Petegem, S., Vansteenkiste, M., Soenens, B., Zimmermann, G., Antonietti, J.-P., Baudat, S., \& Audenaert, E. (2016). When do adolescents accept or defy to maternal prohibitions? The role of social domain and communication style. Journal of Youth and Adolescence. Advance online publication. doi: 10.1007/s10964016-0562-7.

van Prooijen, J. W. (2009). Procedural justice as autonomy regulation. Journal of Personality and Social Psychology, 96, 1166-1180. doi: 10.1037/a0014153

Vansteenkiste, M., \& Ryan, R. M. (2013). On psychological growth and vulnerability: Basic psychological need satisfaction and need frustration as a unifying principle. Journal of Psychotherapy Integration, 23, 263-280. doi: $10.1037 / \mathrm{a} 0032359$

Vansteenkiste, M., Simons, J., Lens, W., Sheldon, K., \& Deci, E. L. (2004). Motivation learning, performance, and persistence: The synergistic effects of intrinsic goal contents and autonomy-supportive contexts. Journal of Personality and Social Psychology, 87, 246-260. doi: 10.1037/0022-3514.87.2.246

Vansteenkiste, M., Simons, J., Lens, W., Soenens, B., \& Matos, L. (2005). Examining the motivational impact of intrinsic versus extrinsic goal framing and autonomy-supportive versus internally controlling communication style on early adolescents' academic achievement. Child Development, 76, 483-501. doi: 10.1111/j.1467-8624.2005.00858.x

Vansteenkiste, M., Soenens, B., Van Petegem, S., \& Duriez, B. (2014). Longitudinal associations between adolescent perceived style of parental prohibition and oppositional defiance and internalization. Developmental Psychology, 50, 229-236. doi: 10.1037/a0032972

Weinstein, N., \& Ryan, R. M. (2011). A self-determination theory approach to understanding stress incursion and responses. Stress \& Health, 27, 4-17. Doi: 10.1002/smi.1368 
Zimmer-Gembeck, M. J., Ducat, W., \& Collins, W. A. (2011). Autonomy development during adolescence. In B. B. Brown \& M. Prinstein (Eds.), Encyclopedia of adolescence (pp. 66-76). New York: Academic Press.

Zimmer-Gembeck, M. J., \& Locke, E. M. (2007). The socialization of adolescent coping behaviors: Relationships with families and teachers. Journal of Adolescence, 30, 1-16. doi: 10.1016/j.adolescence.2005.03.001

Zimmer-Gembeck, M. J., \& Skinner, E. A. (2011). The development of coping across childhood and adolescence: An integrative review and critique of research. International Journal of Behavioral Development, 35, 1-17. doi: $10.1177 / 0165025410384923$

Zimmer-Gembeck, M. J, \& Skinner, E. A. (2016). The development of coping and regulation: Implications for psychopathology and resilience. In D. Cicchetti (Ed.) Developmental psychopathology (3rd ed., Vol. 4, pp. 485-544). New York, NY: Wiley. 
Table 1

Means, Standard Deviations and Correlations among the Variables of Study 1

\begin{tabular}{|c|c|c|c|c|c|c|c|c|c|}
\hline & Mean & $S D$ & 1 & 2 & 3 & 4 & 5 & 6 & 7 \\
\hline 1. Situation ${ }^{\mathrm{a}}$ & 0.49 & 0.50 & & & & & & & \\
\hline 2. Context $\mathrm{t}^{\mathrm{b}}$ & 3.74 & 0.53 & .03 & & & & & & \\
\hline 3. Perceived parental autonomy support & 2.98 & 1.00 & $.66 * * *$ & $.17^{*}$ & & & & & \\
\hline 4. Perceived parental control & 2.74 & 1.02 & $-.64 * * *$ & $-.29 * * *$ & $-.74 * * *$ & & & & \\
\hline 5. Autonomy need satisfaction & 2.82 & 0.97 & $.67 * * *$ & $.20 * *$ & $.78 * * *$ & $-.76 * * *$ & & & \\
\hline 6. Autonomy need frustration & 3.02 & 0.92 & $-.61 * * *$ & $-.25 * *$ & $-.68 * * *$ & $.76^{* * *}$ & $-.75 * * *$ & & \\
\hline 7. Oppositional defiance & 2.07 & 0.85 & $-.20 * *$ & $-.24 * *$ & $-.36 * * *$ & $.43 * * *$ & $-.36 * * *$ & $.34 * * *$ & \\
\hline 8. Negotiation & 3.82 & 0.72 & -.13 & $.25 * *$ & -.02 & .11 & -.09 & .10 & $-.17 *$ \\
\hline
\end{tabular}

Note. ${ }^{\mathrm{a}} 0=$ controlling situation, $1=$ autonomy-supportive situation. ${ }^{\mathrm{b}}$ Context $=$ Perceived autonomy-supportive parenting context. ${ }^{*} p<.05 .{ }^{* *} p<.01 .{ }^{* * *} p<$ .001 . 
Table 2

Situation and Perceived Parenting Context as Predictors of Adolescents' Appraisals and Coping (Study 1)

\begin{tabular}{|c|c|c|c|c|c|c|}
\hline & \multicolumn{4}{|c|}{ Appraisal } & \multicolumn{2}{|c|}{ Coping } \\
\hline & $\begin{array}{l}\text { Perceived } \\
\text { parental } \\
\text { autonomy } \\
\text { support }\end{array}$ & $\begin{array}{c}\text { Perceived } \\
\text { parental } \\
\text { control }\end{array}$ & $\begin{array}{c}\text { Autonomy } \\
\text { need } \\
\text { satisfaction }\end{array}$ & $\begin{array}{l}\text { Autonomy } \\
\text { need } \\
\text { frustration }\end{array}$ & $\begin{array}{c}\text { Oppositional } \\
\text { defiance }\end{array}$ & Negotiation \\
\hline$F(3,173)$ & $51.54 * * *$ & $54.99 * * *$ & $55.65 * * *$ & $41.61 * * *$ & $6.59 * * *$ & $6.63 * * *$ \\
\hline Situation $^{\mathrm{a}}$ & $.66^{* * *}$ & $-.64 * * *$ & $.67 * * *$ & $-.60 * * *$ & $-.20 * *$ & $-.15^{*}$ \\
\hline Context $^{\mathrm{b}}$ & $.15^{* *}$ & $-.27 * * *$ & $.18 * *$ & $-.23 * * *$ & $-.23 * *$ & $.25^{* *}$ \\
\hline Situation $\times$ Context & $.14^{*}$ & -.05 & .10 & .00 & .09 & $-.15^{*}$ \\
\hline Adjusted $R^{2}$ & .47 & .48 & .49 & .41 & .09 & .09 \\
\hline
\end{tabular}

Note. ${ }^{\mathrm{a}} 0=$ controlling situation, $1=$ autonomy-supportive situation. ${ }^{\mathrm{b}}$ Context $=$ Perceived autonomy-supportive parenting context. $* p<.05 . * * p<.01 . * * * p<$

.001. Standardized regression coefficients are presented. 
Table 3

Results of Latent Class Growth Analyses (Study 2)

\begin{tabular}{|c|c|c|c|c|c|c|c|c|}
\hline \multirow[b]{2}{*}{ Solution } & \multirow[b]{2}{*}{$\mathrm{BIC}$} & \multirow[b]{2}{*}{ AIC } & \multirow[b]{2}{*}{ Entropy } & \multirow[b]{2}{*}{ LMR-LRT } & \multicolumn{3}{|c|}{ Trajectory Classes } & \multirow[b]{2}{*}{4} \\
\hline & & & & & 1 & 2 & 3 & \\
\hline 2-class & 633.37 & 607.77 & .82 & $110.41 * * *$ & & & & \\
\hline Proportion & & & & & 74 & 26 & & \\
\hline Mean I & & & & & $4.22 * * *$ & $3.38^{* * *}$ & & \\
\hline Mean S & & & & & 0.01 & 0.00 & & \\
\hline 3-class & 609.31 & 575.18 & .82 & $36.11 * *$ & & & & \\
\hline Proportion & & & & & 51 & 42 & 7 & \\
\hline Mean I & & & & & $4.27 * * *$ & $3.80 * * *$ & $3.12 * * *$ & \\
\hline Mean S & & & & & $0.04 * *$ & -0.01 & $-0.07^{\dagger}$ & \\
\hline 4-class & 608.46 & 565.79 & .74 & 14.39 & & & & \\
\hline Proportion & & & & & 46 & 27 & 20 & 7 \\
\hline Mean I & & & & & $4.13^{* * *}$ & $4.35 * * *$ & $3.51^{* * *}$ & $3.13 * * *$ \\
\hline Mean S & & & & & -0.02 & $0.05 * *$ & 0.03 & $-.07^{\dagger}$ \\
\hline
\end{tabular}


Table 4

F-values and $\eta^{2}$-values for the RM MANOVAs predicting adolescents' appraisals and coping reactions, for Study 2

\begin{tabular}{|c|c|c|c|c|c|c|}
\hline & \multicolumn{2}{|c|}{ Situation } & \multicolumn{2}{|c|}{ Context Trajectory } & \multicolumn{2}{|c|}{ Situation $\times$ Context Trajectory } \\
\hline & $F$ & $\eta^{2}$ & $F$ & $\eta^{2}$ & $F$ & $\eta^{2}$ \\
\hline \multicolumn{7}{|l|}{ Appraisal } \\
\hline Autonomy Need Satisfaction & $188.18 * * *$ & .60 & 2.38 & .04 & $6.24 * *$ & .09 \\
\hline Autonomy Need Frustration & $104.63 * * *$ & .46 & $4.13 *$ & .06 & $6.21 * *$ & .09 \\
\hline \multicolumn{7}{|l|}{ Coping } \\
\hline Oppositional Defiance & $53.24 * * *$ & .30 & $4.32 *$ & .07 & $3.42 *$ & .05 \\
\hline Submission & $56.15 * * *$ & .31 & $4.77 *$ & .07 & $7.77 * * *$ & .11 \\
\hline Negotiation & $7.69 * *$ & .06 & $13.59 * * *$ & .18 & $8.45 * * *$ & .12 \\
\hline Accommodation & $29.90 * * *$ & .19 & 1.49 & .02 & 0.84 & .01 \\
\hline
\end{tabular}

Note. ${ }^{*} p<.05 . * * p<.01 . * * * p<.001$. 


\section{Figures}
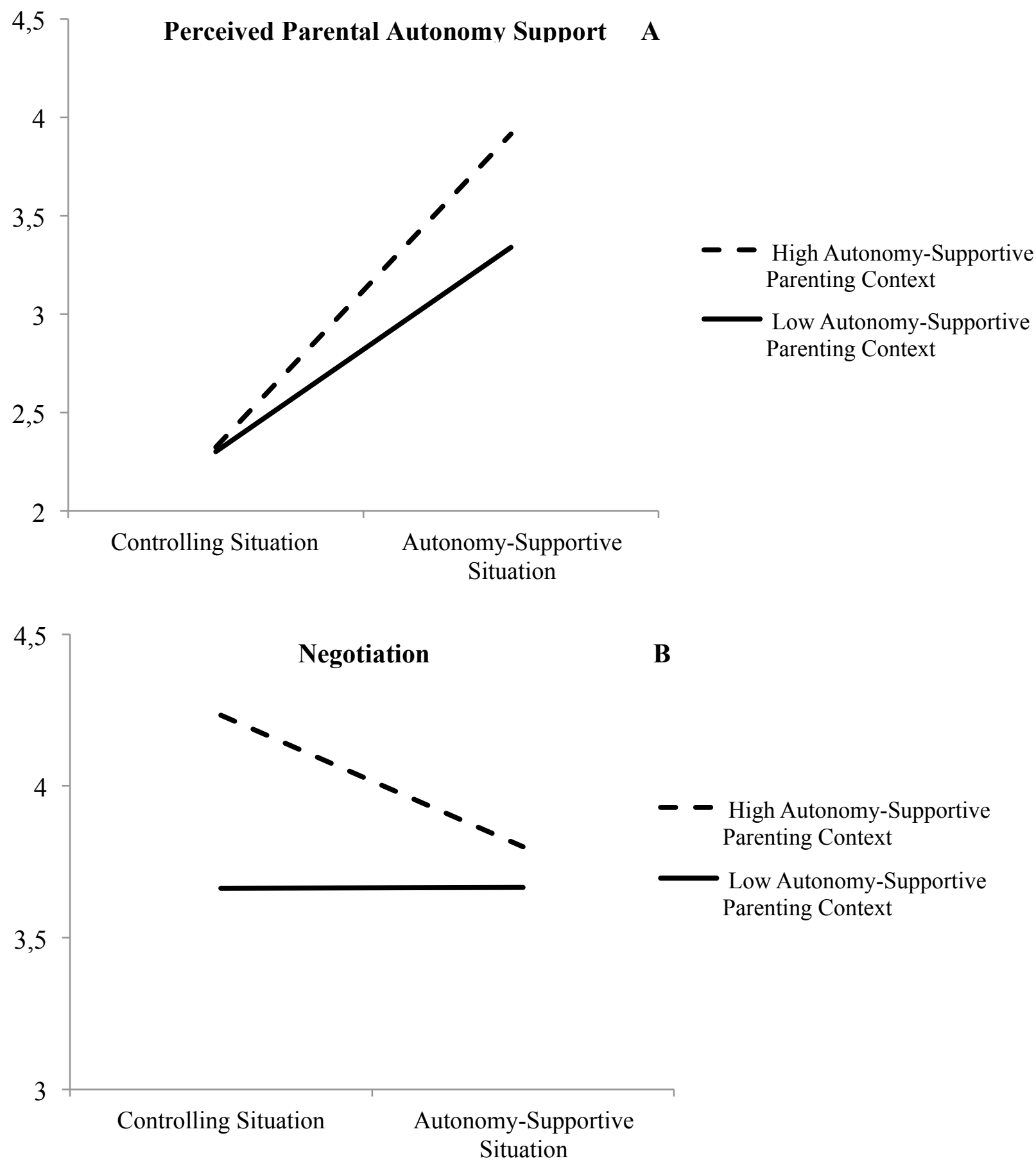

Figure 1. Interaction between situation and perceived parenting context in the prediction of perceived parental autonomy support (A) and negotiation (B) for Study 1 


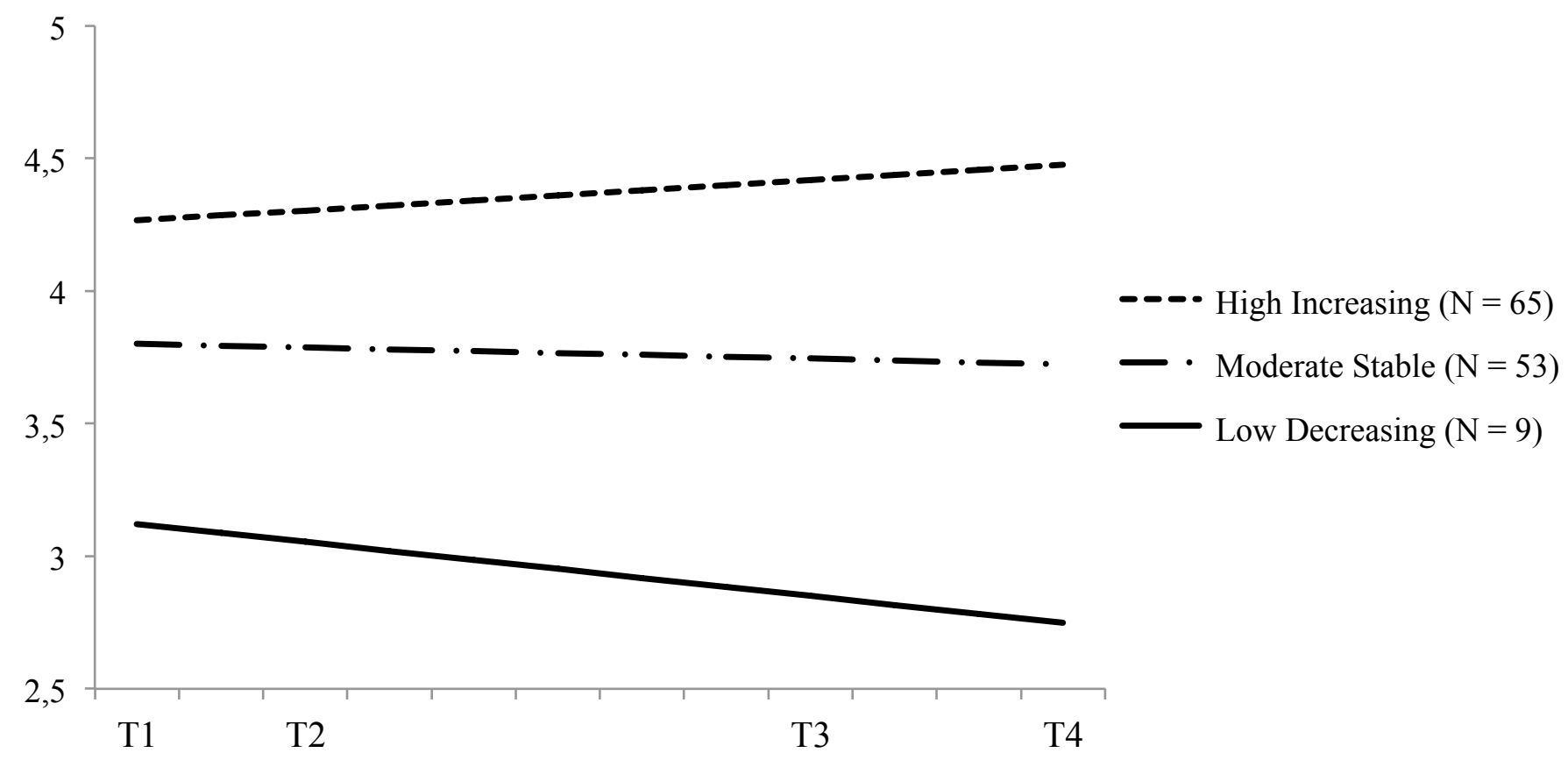

Figure 2. Estimated mean values for perceived autonomy-supportive parenting context for the three parentingtrajectory classes (Study 2). 
Autonomy Need Satisfaction

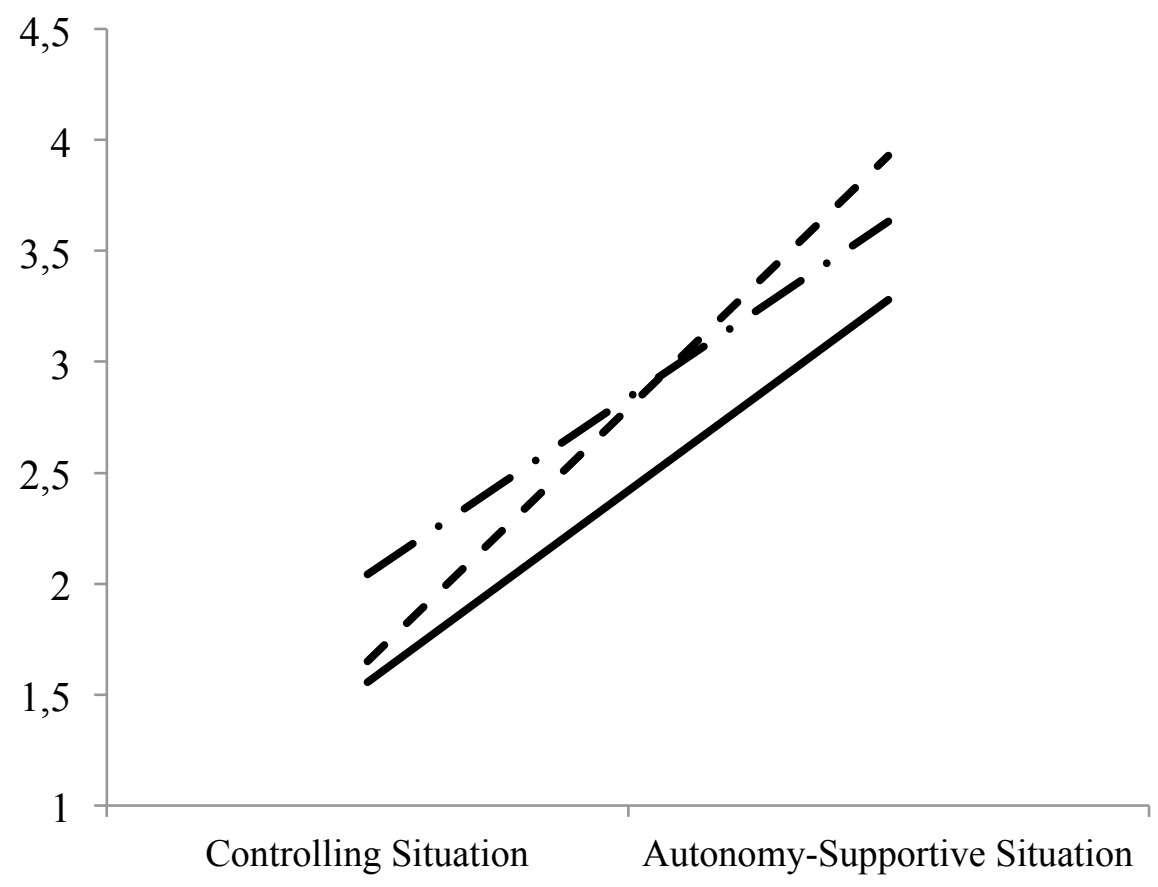

Autonomy Need Frustration

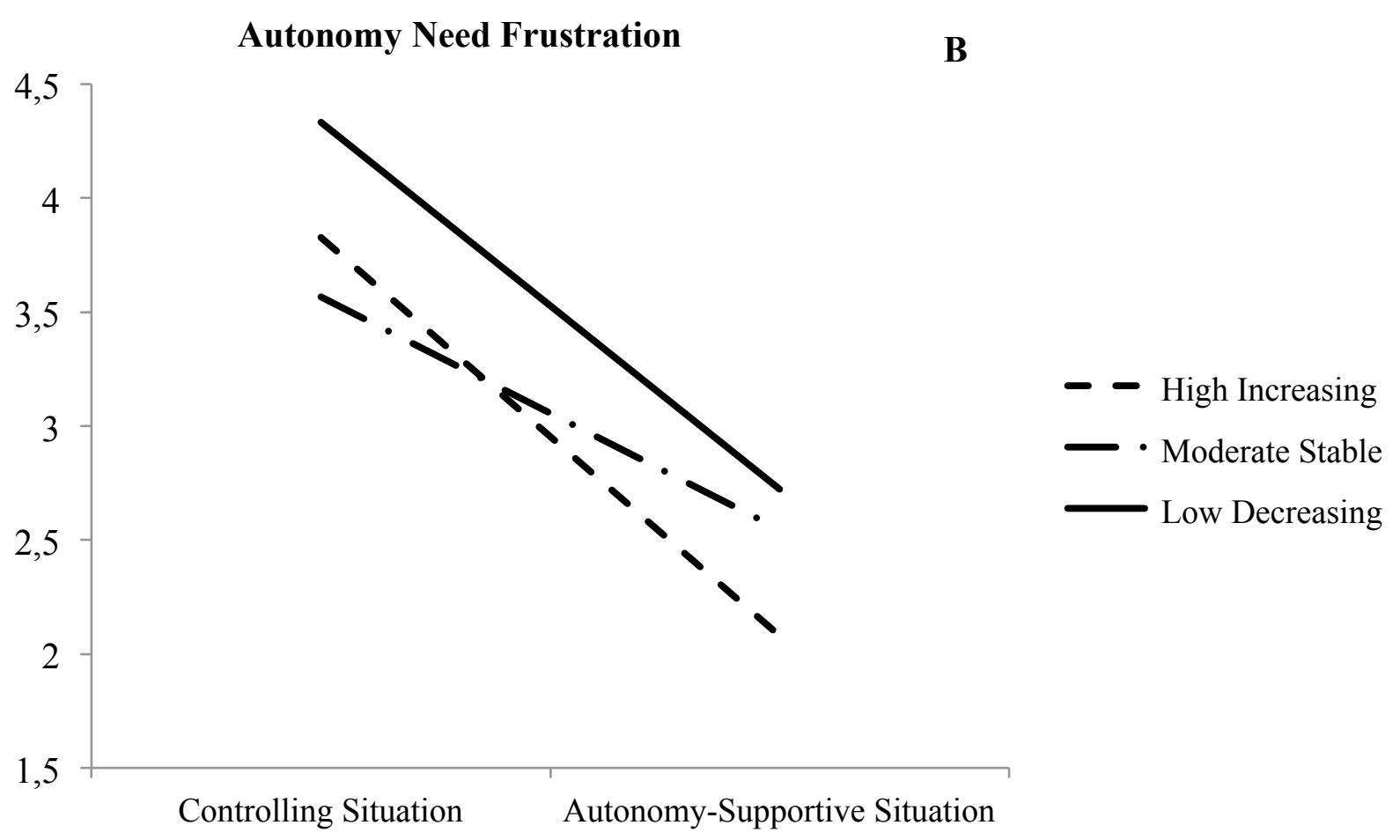

- High Increasing

- Moderate Stable Low Decreasing

Figure 3. Interaction between situation and perceived parenting context trajectory in the prediction of experienced autonomy need satisfaction (A) and autonomy need frustration (B) for Study 2 


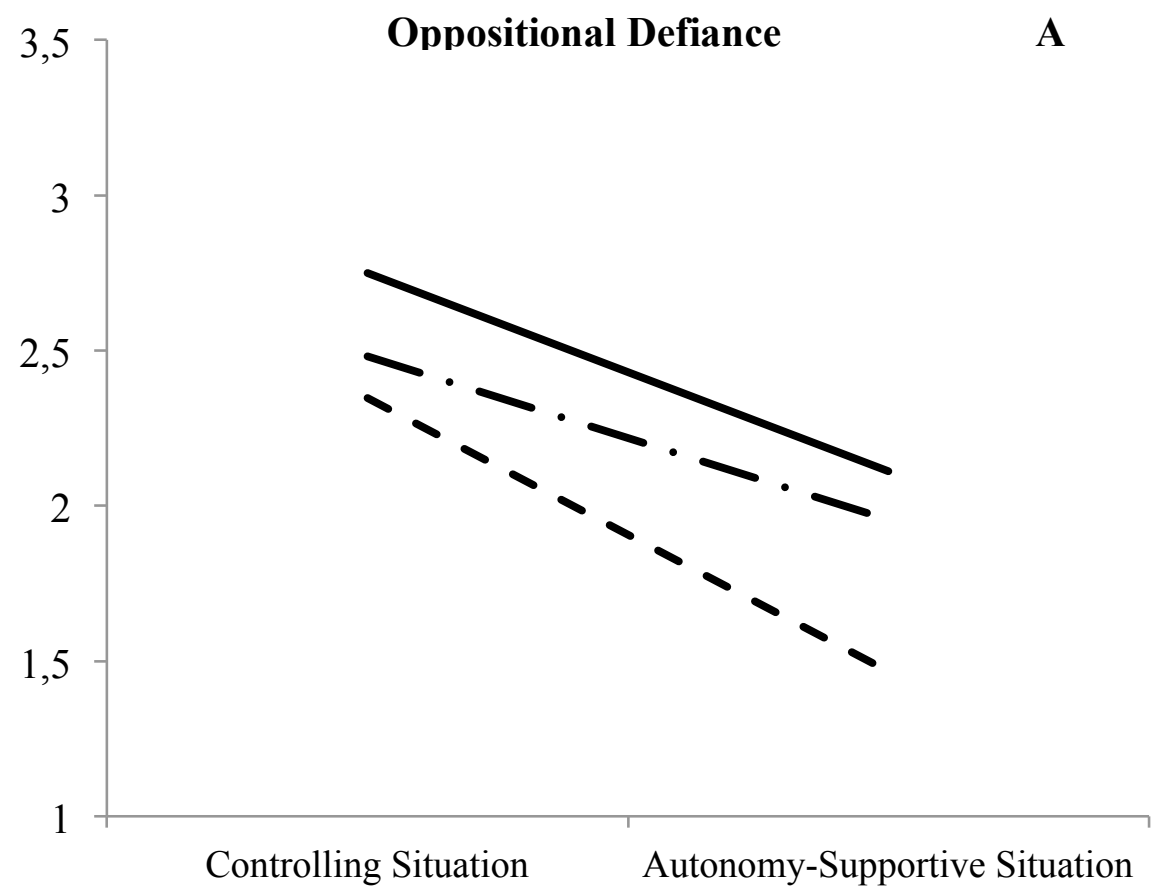

- - High Increasing

— Moderate Stable Low Decreasing

Submission

B

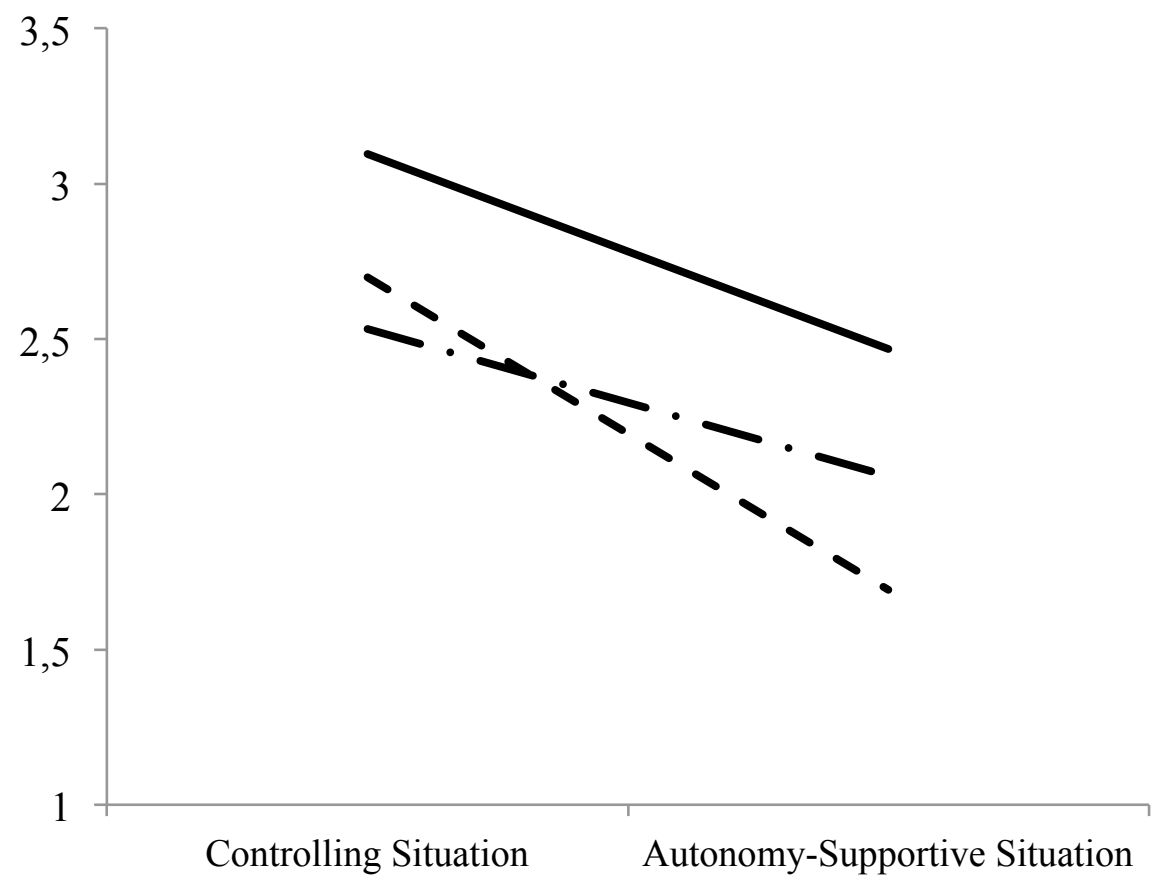

- - High Increasing

— Moderate Stable Low Decreasing 


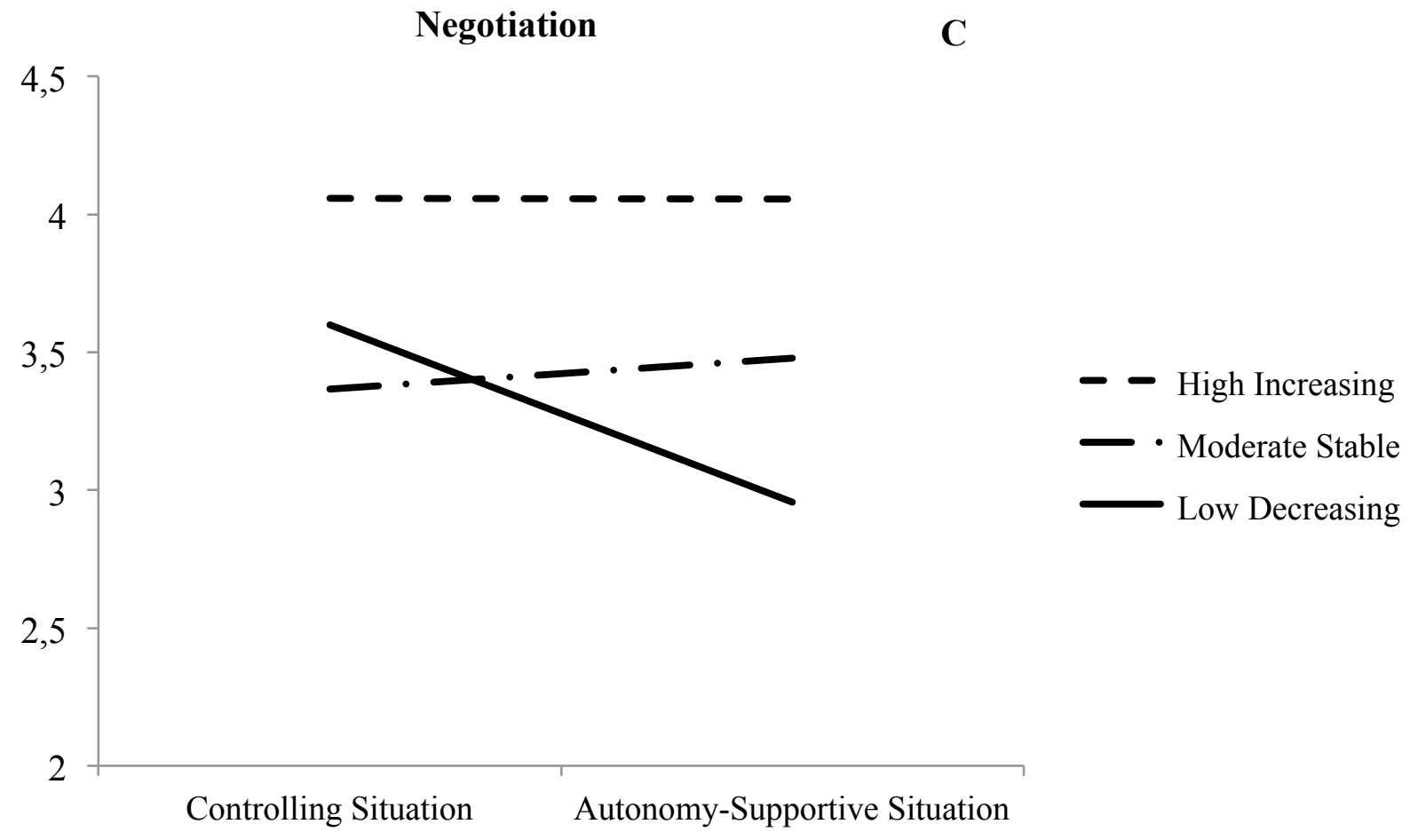

Figure 4. Interaction between situation and perceived parenting context trajectory in the prediction of oppositional defiance (A), submission (B), and negotiation (C) for Study 2 